\title{
Research Paper: \\ Comparison of the Childhood Trauma, Mindfulness Attention Awareness and Inte- grative Self Knowledge in Cancer Patients and General Population
}

\author{
Mohammad Saeed Khanjani ${ }^{1}$ (), ${ }^{*}$ Shadan Mosavat ${ }^{1}$ (), Bahman Bbahmani ${ }^{1}$ (i), Enayatollah Bakhshi ${ }^{2}$ (1)
}

1. Department of Counseling, University of Social Welfare and Rehabilitation Sciences, Tehran, Iran

2. Department of Statistics, University of Social Welfare and Rehabilitation Sciences, Tehran, Iran

\begin{tabular}{|l|l|l|l}
\hline $\begin{array}{c}\text { Use yourdevice to scan } \\
\text { and read the article online }\end{array}$ & $\begin{array}{l}\text { Crtation Khanjani MS, Mosavat Sh, Bbahmani B, Bakhshi E. [Comparison of the Childhood Trauma, Mindfulness Attention } \\
\text { Awareness and Integrative Self Knowledge in Cancer Patients and General Population (Persian)].Iranian Journal of Psychiatry and } \\
\text { Clinical Psychology. 2021; 27(1):32-47. http://dx.doi.org/10.32598/ijpcp.27.1.3187.1 }\end{array}$ \\
doj'http://dx.doi.org/10.32598/ijpcp.27.1.3187.1
\end{tabular}

Received: 06 Sep 2019 Accepted: 11 May 2020 Available Online: 01 Apr 2021

Key words: Integrative self-knowledge, Mindfulness, Childhood trauma, Cancer

\section{A B STRACT}

Objectives This study aims to compare childhood trauma, integrative self-knowledge and mindfulness in patients with cancer and healthy people.

Methods This descriptive-analytical study was conducted on 139 patients with cancer and 139 healthy people referred to Firoozgar Hospital and SAMAR Charity House who were selected by a convenience sampling method. They were asked to complete Integrative Self-Knowledge (ISK) Questionnaire, Childhood Trauma Questionnaire (CTQ) and Mindfulness Attention Awareness Scale (MAAS). Data were analyzed using descriptive and inferential statistic methods including MANOVA.

Results There was a significant difference between patients and controls in terms of ISK $(P<0.001)$, mindfulness $(P<0.001)$ and childhood trauma $(P<0.001)$.

Conclusion Cancer patients have lower ISK and mindfulness but higher childhood trauma compared to healthy people. Attention should be paid to the role of these factors in prevention and treatment processes.

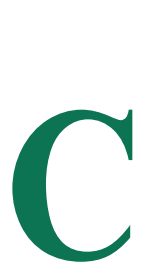

\section{Extended Abstract}

\section{Introduction}

ancer is a chronic disease responsible for high number of deaths in the world. Given the rising trend of this disease in the world including Iran, there is a need to address its various aspects. Several studies have been conducted on the causes of cancer. The hypothesis that psychological factors related to stress have an effect on the onset of cancer has long been considered by many researchers and some have reported contradictory results. Some studies have differentiated stressors in terms of being chronic or acute. One of chronic stressor is childhood trauma. Our experiences in childhood will be the basis of our mental and physical health in adulthood. It is obvious that stressful events especially chronic stressors can impair our immune system and make us prone to diseases.

Another psychological factor that affects the past and present of the person is Integrative Self-Knowledge (ISK) which reflects one's past, present and future self-experience. If a person faces traumatic events in childhood, such events will affect their ISK. When facing traumatic events, people give habit-based responses without thinking and understanding the event to control the environment. This is called mindfulness which is the ability to be present at the moment without judgment. Its seems that childhood trauma may limit one's ability to understand the present situations

* Corresponding Author:

Shadan Mosavat, MA.

Address: Department of Counseling, University of Social Welfare and Rehabilitation, Tehran, Iran.

Tel: +98 (21) 22131153

E-mail: shadanmosavat@yahoo.com 
Table 1. Mean scores of CTQ, MAAS and ISK in the study groups

\begin{tabular}{ccc}
\hline \multirow{2}{*}{ Variable } & & Mean \pm SD \\
\cline { 2 - 3 } & Patients & Controls \\
\hline CTQ & $87.27 \pm 13.68$ & $47.12 \pm 12.81$ \\
MAAS & $52.30 \pm 16.88$ & $68.47 \pm 15.68$ \\
ISK & $28.19 \pm 10.06$ & $38.09 \pm 9.40$ \\
\hline & & Iranian Journal of \\
PSYCHIATRY AND CUNICAL PSYCHOLOGY
\end{tabular}

SD= Standard deviation; CTQ: Childhood Trauma Questionaire; MAAS: Mindful Attention Awareness; ISK: Integrative Self Knowledge.

without judgment. Study of the relationship between thee mentioned psychological factors and cancer can help use preventive and interventional strategies to reduce the incidence of trauma in future generations.

\section{Methods}

This descriptive-analytical study was conducted on 139 patients with cancer and 139 healthy people referred to Firoozgar Hospital and SAMAR Charity House who were selected by a convenience sampling method. The sample size was determined using Cohen's formula by considering a test error of $5 \%$ and test power of $80 \%$. Participants were asked to complete ISK questionnaire, Childhood Trauma Questionnaire (CTQ) and Mindfulness Attention Awareness Scale (MAAS). Data were analyzed using descriptive statistics (mean, standard deviation) and inferential statistics including MANOVA.

\section{Results}

Based on the results of MANOVA, there was a significant difference between the two groups in terms of childhood trauma $(\mathrm{P}=0.001)$, ISK $(\mathrm{P}=0.001)$, and mindfulness $(\mathrm{P}=0.001)$ (Tables 1 and 2). Healthy people had higher ISK and MAAS scores and lower CTQ score compared to cancer patients.

\section{Discussion and Conclusion}

According to the findings of the present study, there was a significance difference between cancer patients and healthy people in three psychological factors (childhood trauma, mindfulness, and ISK). Cancer patients had lower ISK and mindfulness but higher childhood trauma in comparison with healthy people. So far, there have been no study on the ISK of cancer patients but some studies have shown the relationship of this variable with depression and anxiety [16]. Regarding mindfulness, we found no similar study on cancer patients, but some studies examined mindful attention awareness and they have proved its role in physical and mental health also in the immune system's function [20].

Having cancer and the inevitability of living with it can be one of the most painful stages of any human life. Special attention should be paid to its prevention, diagnosis and early treatment. The relationship between mind and body is one of the most important relationships that has been widely considered in recent years. Our mind and what happens to it simply can affect our body, and there should be a mecha-

Table 2. MANOVA results of comparing CTQ, MAAS and ISK scores between the study groups

\begin{tabular}{rrrcccc}
\hline Source & Sum of Squares & df & Mean Squared & F & Sig. & Test Power \\
\hline CTQ & 112041.586 & 1 & 112041.586 & 637.554 & $<0.001$ & 0.698 \\
\hline Error & 48503.309 & 276 & 175.737 & & & 0.206 \\
\hline ISK & 6810.705 & 1 & 6810.705 & 71.806 & $<0.001$ & 0.199 \\
\hline Error & 26178.101 & 276 & 71.848 & & & $<0.001$ \\
\hline MAAS & 18161.903 & 1 & 18161.903 & 68.386 & & \\
\hline Error & 73299.914 & 276 & 265.579 & & & \\
\hline
\end{tabular}


nism to justify this effect. The role of environmental and genetic factors in cancer development is obvious, but the role of psychological factors is still unclear. Further studies are needed to investigate their role.

\section{Ethical Considerations}

\section{Compliance with ethical guidelines}

This study was approved by Ethics Committee of University of Social Welfare and Rehabilitation Sciences (Code: IR.USWR.REC.1397.146). All ethical principles are considered in this article. The participants were informed about the purpose of the research and its implementation stages. They were also assured about the confidentiality of their information and were free to leave the study whenever they wished, and if desired, the research results would be available to them.

\section{Funding}

The paper was extracted from the MA. thesis of the second author at Department of Counseling, University of Social Welfare and Rehabilitation, Tehran.

\section{Authors contributions}

Conceptualization, methodology, editing \& review: All authors; Investigation, resources, original draft preparation, visualization: Shadan Mosavat; Supervision: Mohammad Saeed Khanjani, Bahman Bahmani; Data analysis: Enayatollah Bakhshi.

\section{Conflicts of interest}

The authors declare no conflict of interest.

\section{Acknowledgements}

The authors would like to thank the staff of SAMAR Charity House and Firoozgar Hospital. 


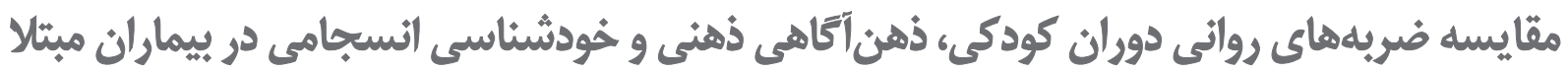
به سرطان با جمعيث عاديث روافي دورى

\author{
محمدسعيد خانجانى' (1) ، "شادان مساوات' (1)، بهمن بهمنى' (1)، عنايتالله بخشى \\ 1. كروه مشاوره، دانشكاه علوم توانبخشى و سلامت اجتماعى، تهران، ايران.

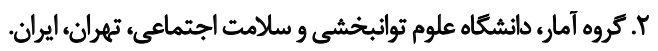

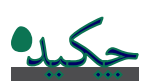

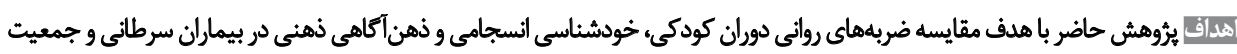
عادى انجام شده است.

هولد وروشى هام مطالعه از نوع توصيفى تحليلى بوده است.

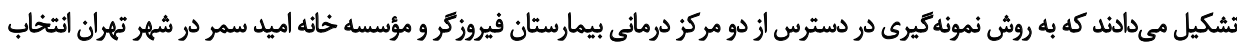

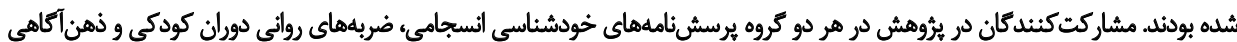

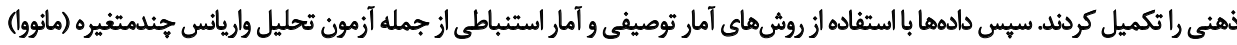
تحليل و تفمير شدندي.

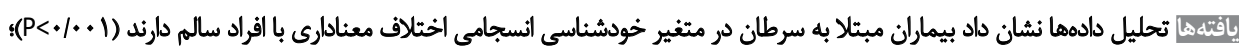

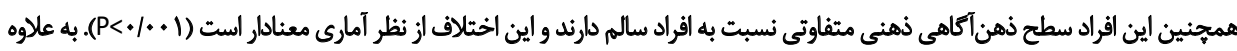

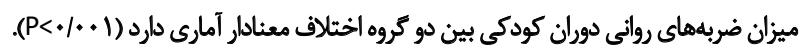

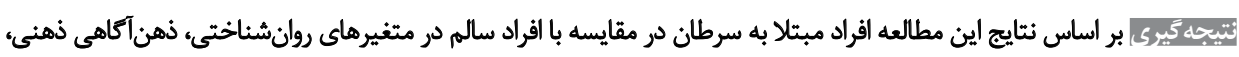

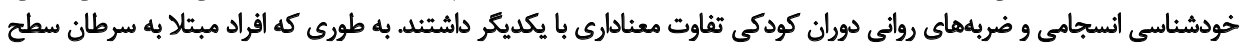

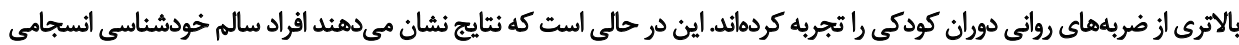

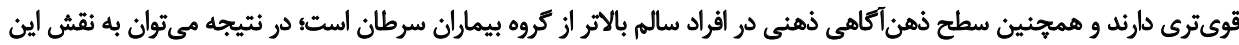

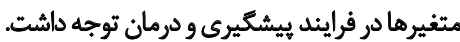

تاريخ دريافت: ها شهريور 1494

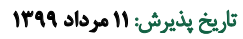

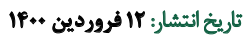

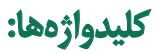
خودشناسى انسجامى،

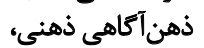
ضربهماي روائي دوران كودكى، سرطان

مرتبط با استرس ثأثيراتى بر شروع و ويشرفت سرطان دارند از

مقام

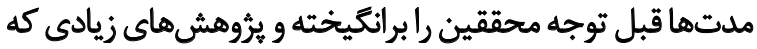

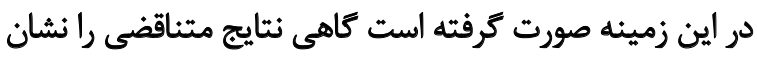

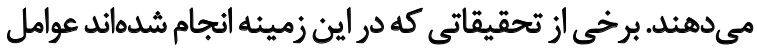

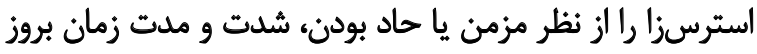

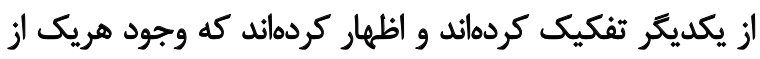

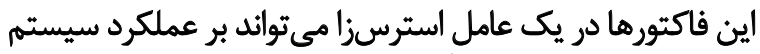

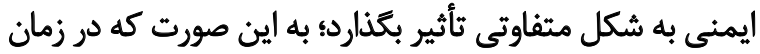

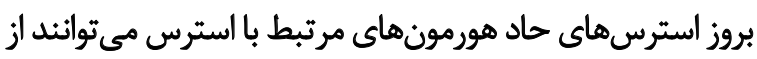

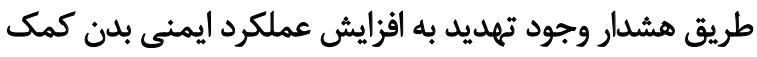

سرطان يكى از انواع بيمارىهاى مزمن است كه تاكنون آمار

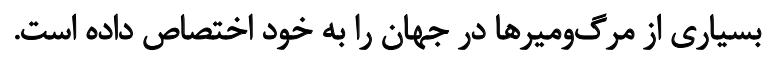

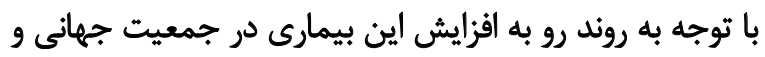

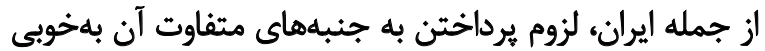

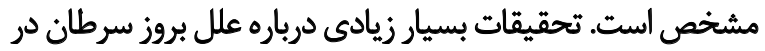

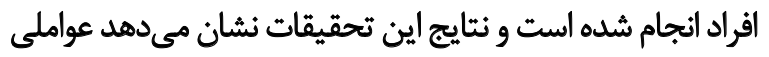

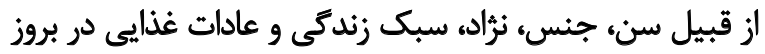
سرطان مؤثر هستند [1]] اين فرضيه كه عوامل روانشناختى سنى

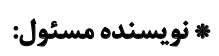
شادان مساوات نشانىى: تهران، دانشكاه علوان توان توانبخشى و سلامت اجتماعيء كروه مشاوره.

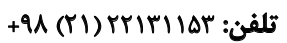
يست الكترونيكي: Shadanmosavat@yahoo.com 
درواقع تحريك بيش از اندازه سيستم ايمنى مى تواند بر رشد و وري

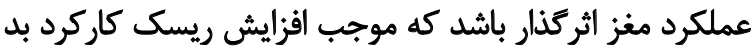

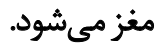

از جمله متغيرهاى روانشناختى كه با تمام كذشته و ورال

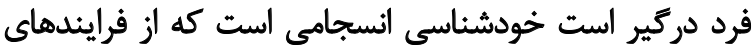

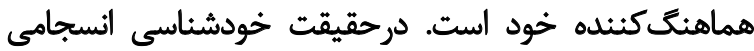

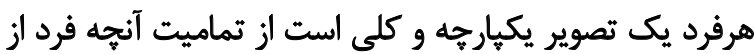

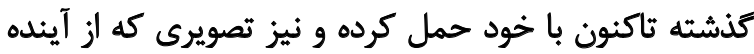

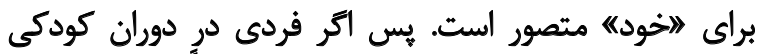

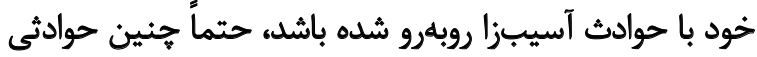

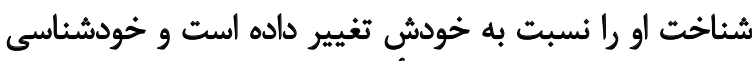

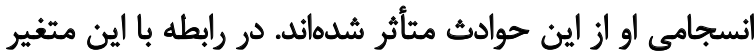

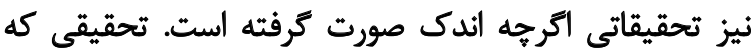

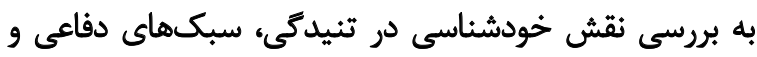

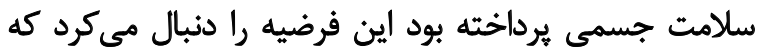

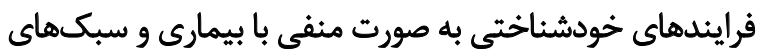

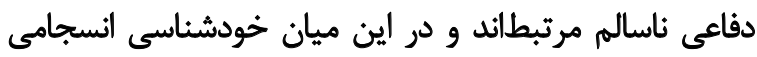

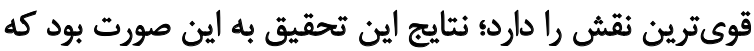

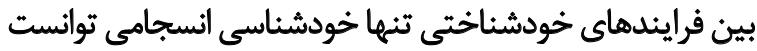

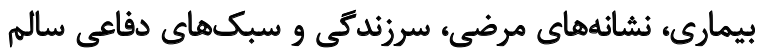

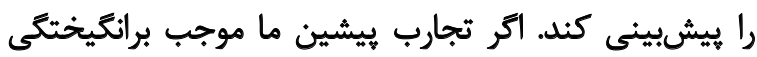

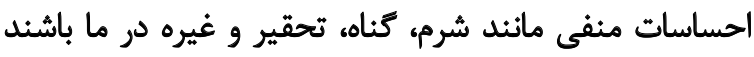

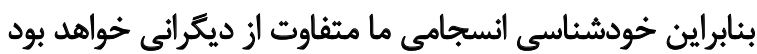
كه تجارب اين جنينى نداشتهاند.

در همين راستا افراد در زمان رويارويى باحوادث و اتفاقات ناكوار

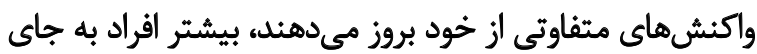

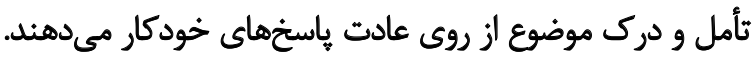

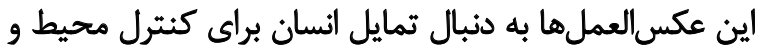

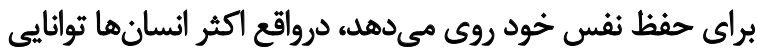

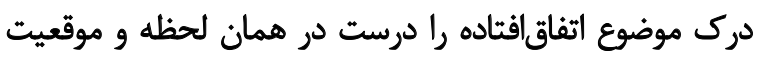

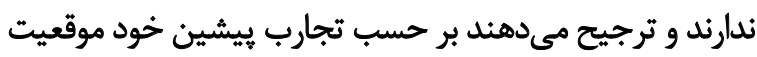

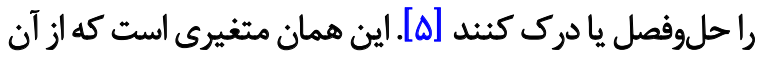

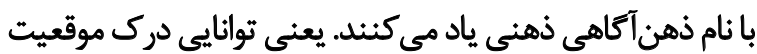

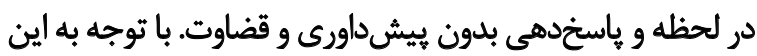

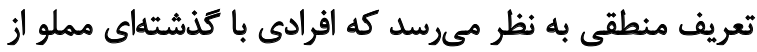

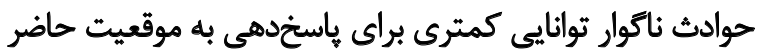

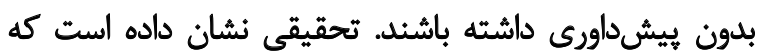

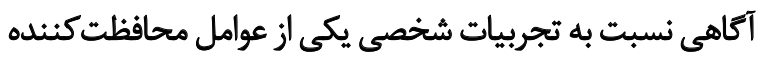

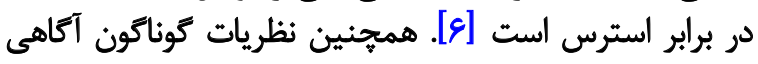

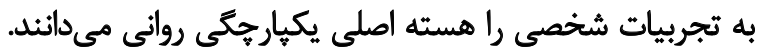

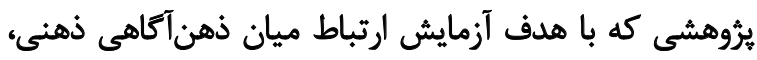

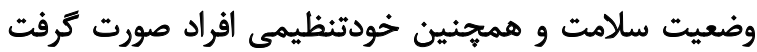

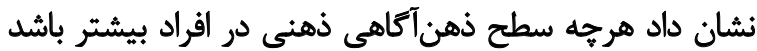

كنند. در حالى كه استرسهاى مزمن موجب فرسودكىى، رنج إنج

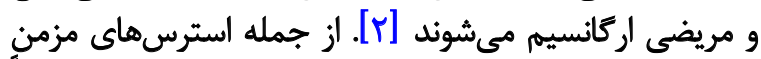

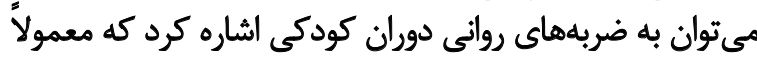

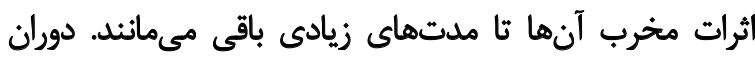

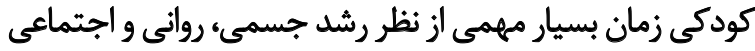

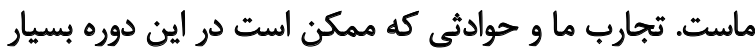

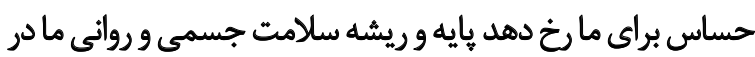

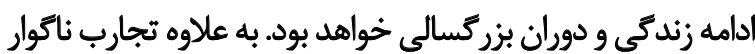

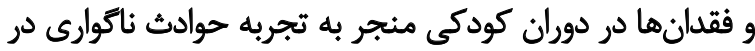

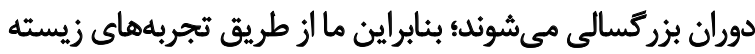

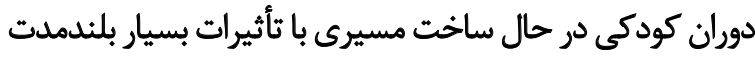

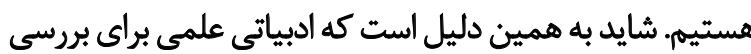

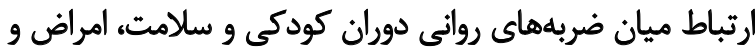

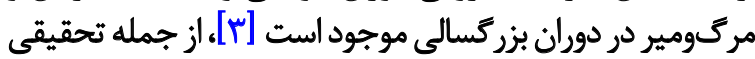

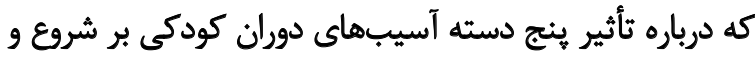

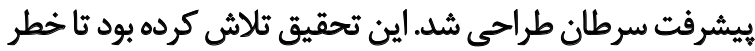

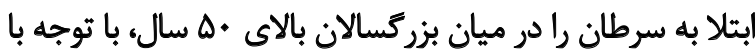

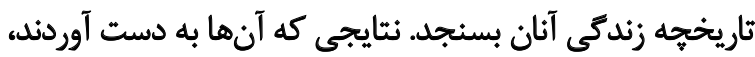

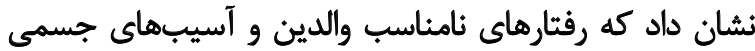

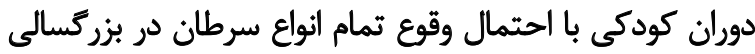

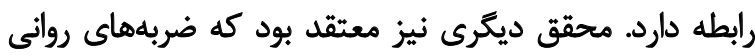

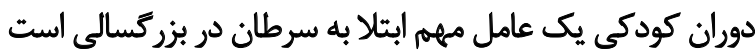

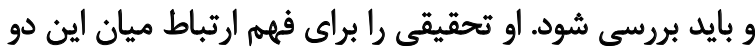

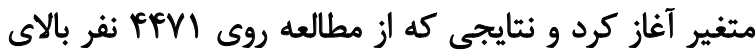

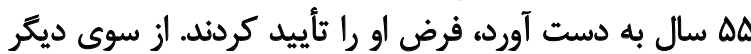

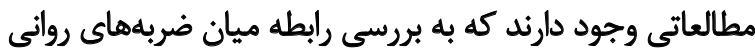

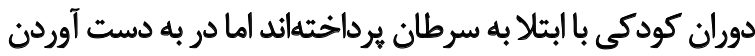

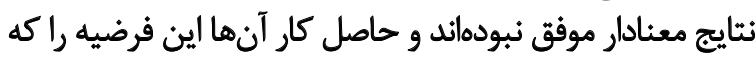

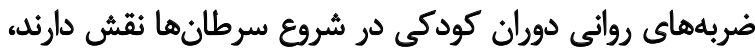

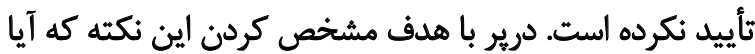

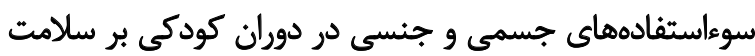

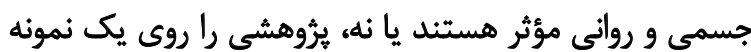

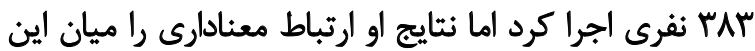

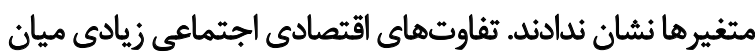

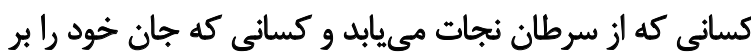

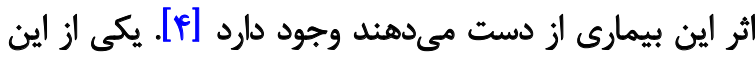

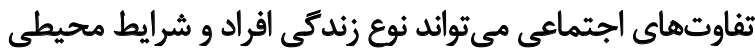

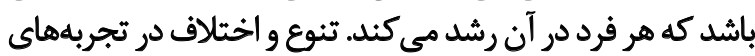

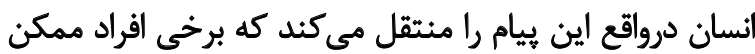

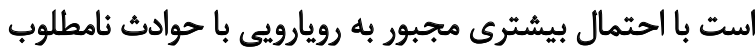

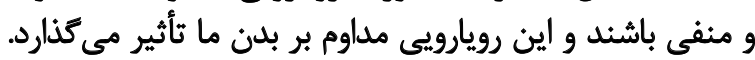

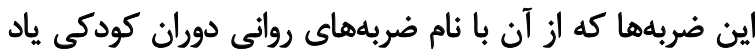

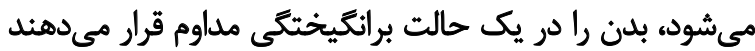

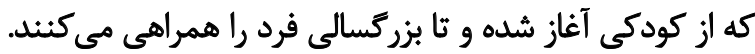




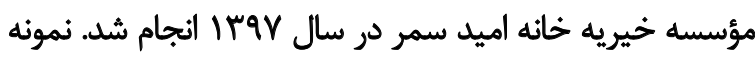

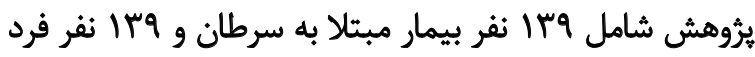

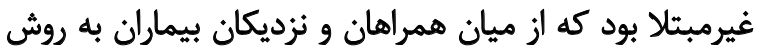

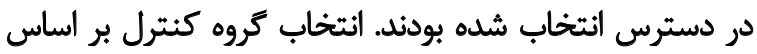

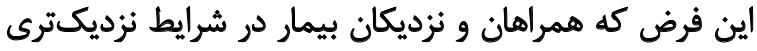

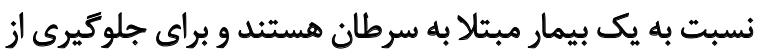

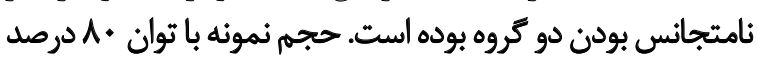

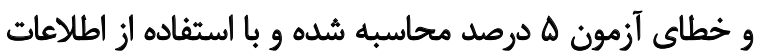

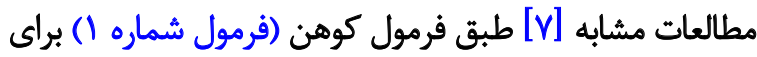
هر كروه به دست آمده است:

$$
\begin{aligned}
& n=\frac{\left[Z_{1} \frac{\text { t }}{2} Z_{1-\beta}\right]^{2}\left(2 \sigma^{2}\right)_{1}}{d^{2}}= \\
& \frac{(1.96+0.84)^{2}\left(2 \times 7.43^{2}\right)}{(22.1-19.6)^{2}}=138.9=139
\end{aligned}
$$

ملاكهاى ورود به ئروهش بالاى 11 سال بودن و داشتن

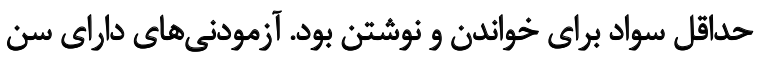

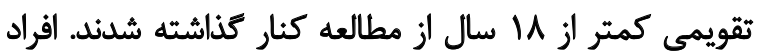

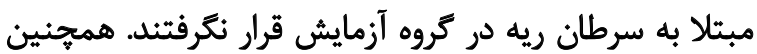

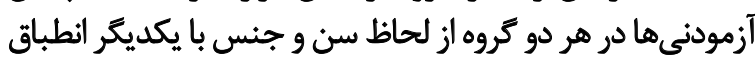

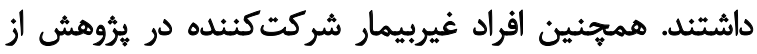

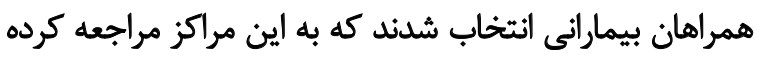

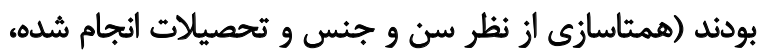

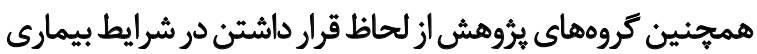

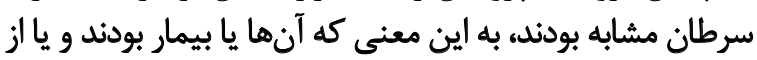

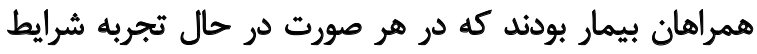

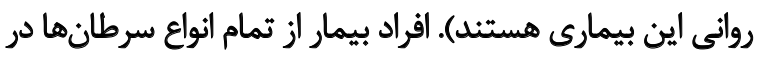

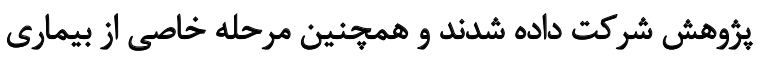

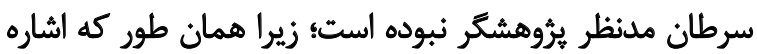

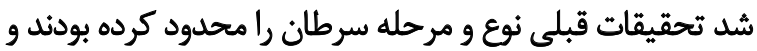

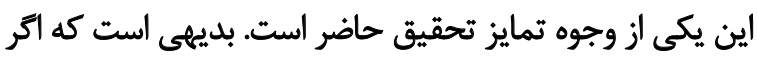

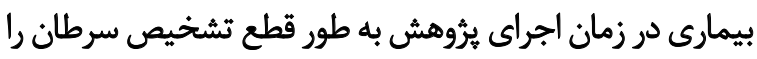

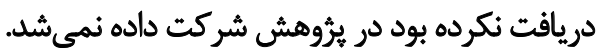

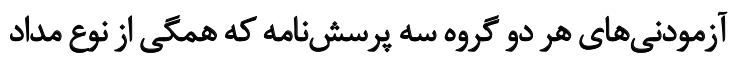

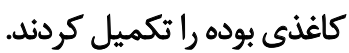

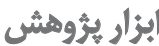

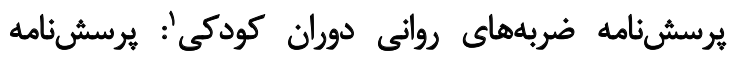

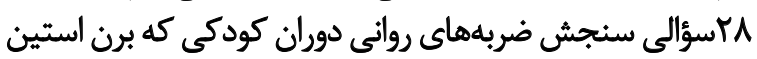

1. Childhood Trauma Questionnaire (СТQ)

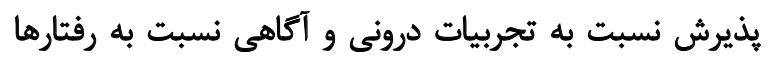

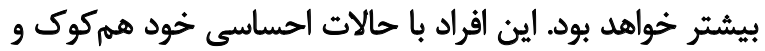

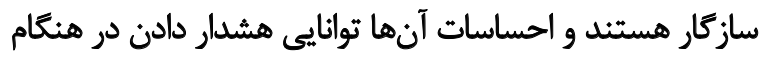

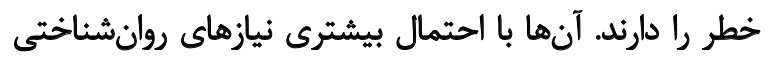

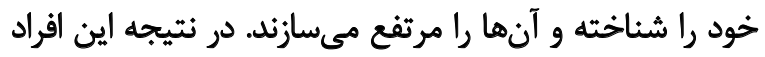

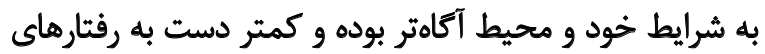

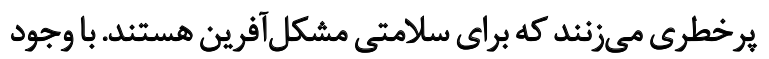

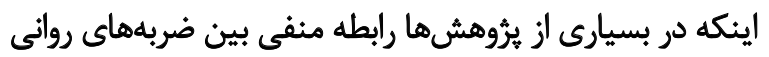

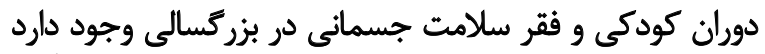

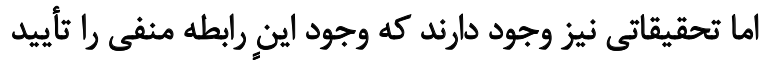

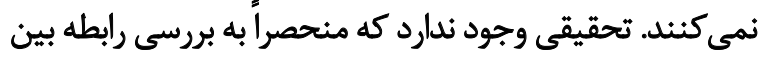

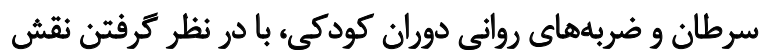

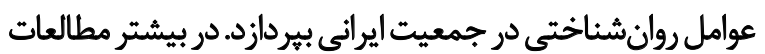

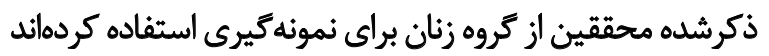

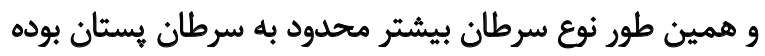

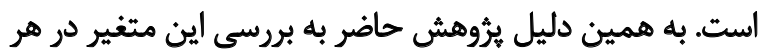

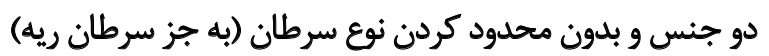

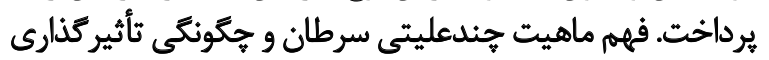

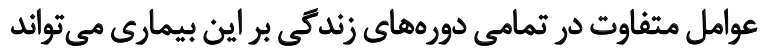

$$
\text { موجب كسترش استراترى هاى يُشيشيرى شود. }
$$

مطالعه و بررسى ارتباط ميان ابتلا به سرطان و مؤلفههاى

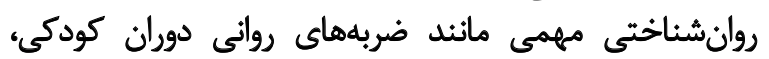

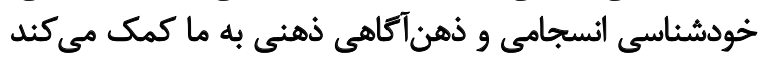

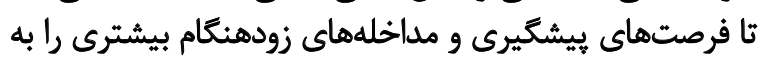

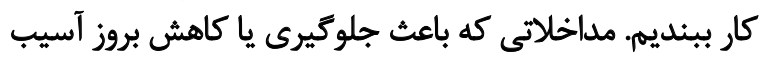

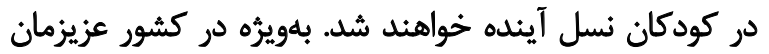

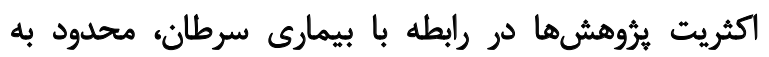

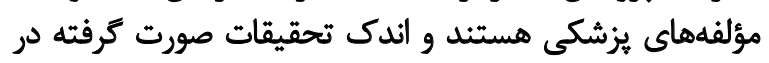

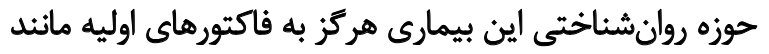

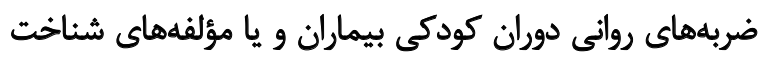

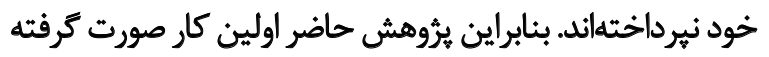

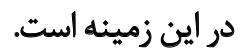

با توجه به اين توضيحات به نظر مىرسد خود و مؤلفههاى

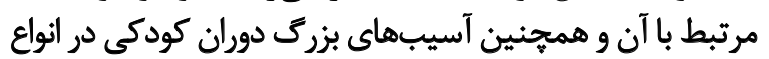

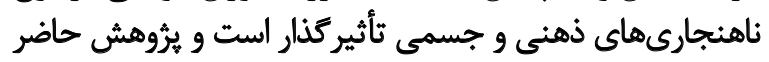

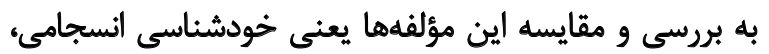

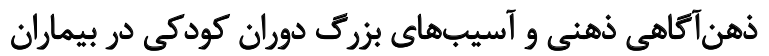
مبتلا به سرطان و جمعيت عادى مي يردازد.

روشى جامعه آمارى، نمونه و ووش الجراى بثروهش اين مطالعه به روش توصيفى تحليلى و در جامعه بيماران مبتئلا

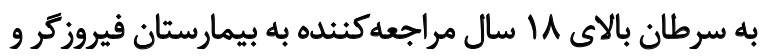




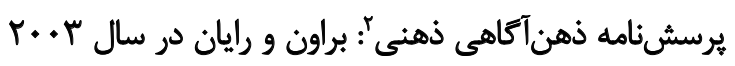

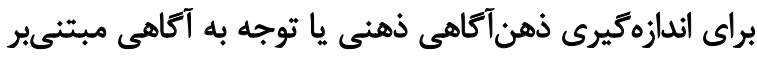

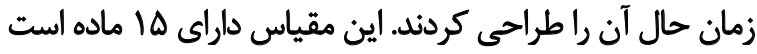

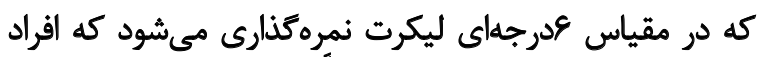

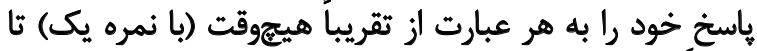

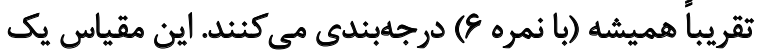

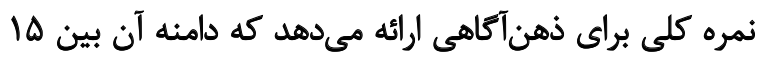

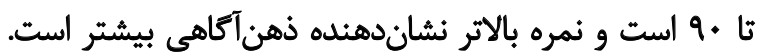

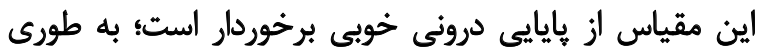

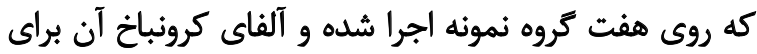

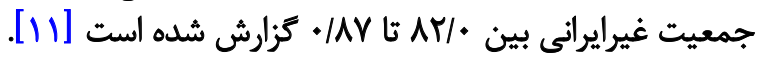

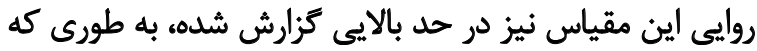

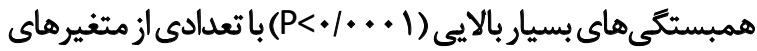

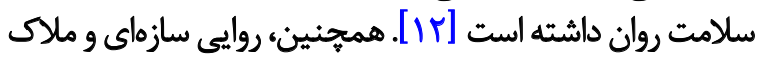

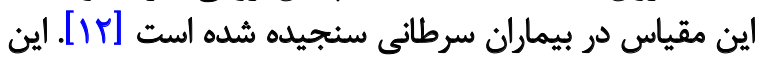

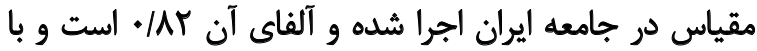

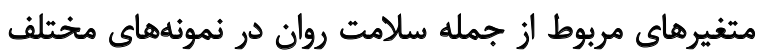

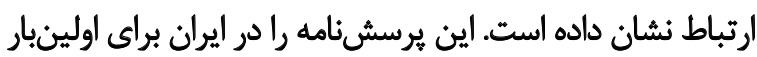

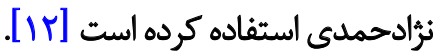

يرسش نامه خودشناسى انسجامى": قربانى، واتسون و هارگيس

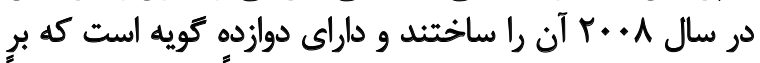

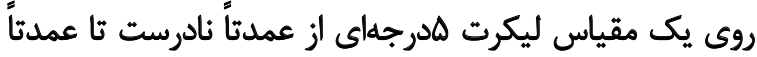

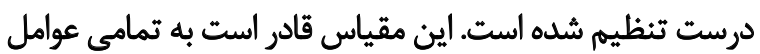

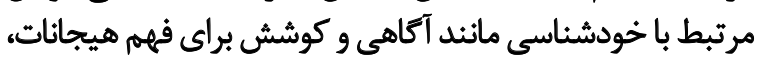

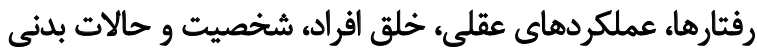

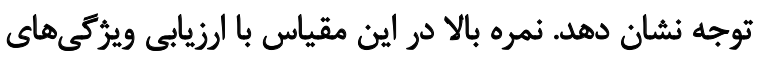

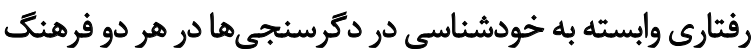

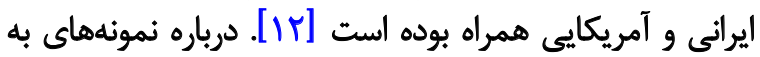

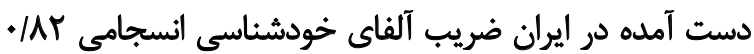

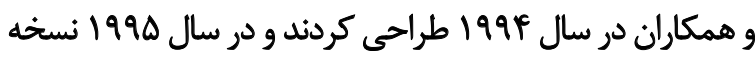

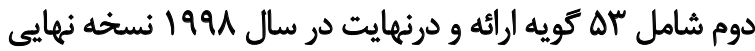

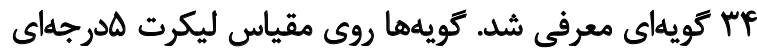

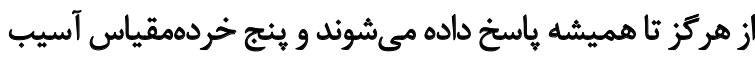

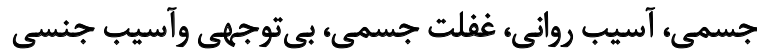

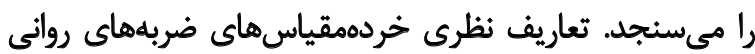

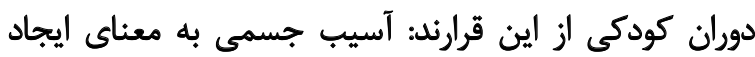

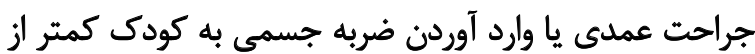

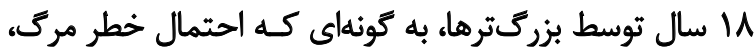

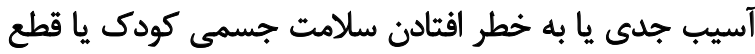

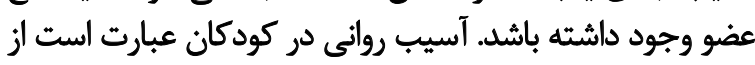

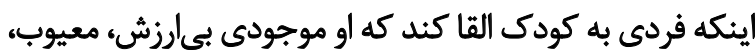

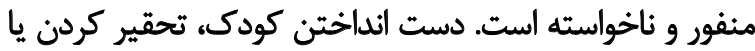

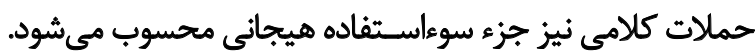

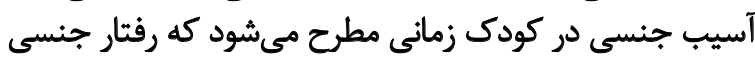

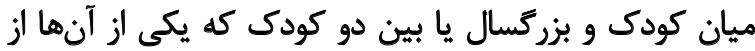

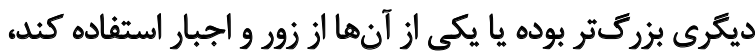

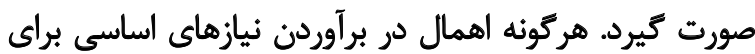

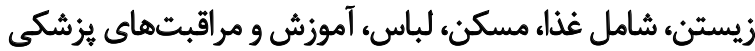

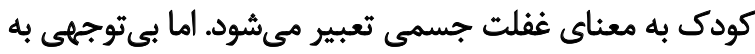

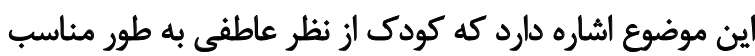

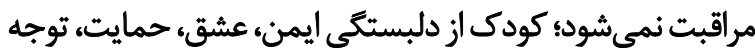

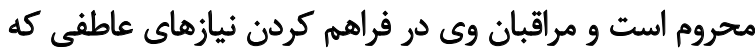

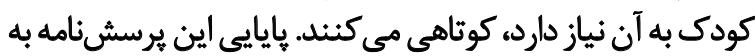

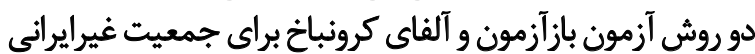

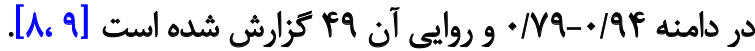

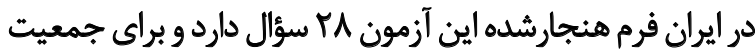

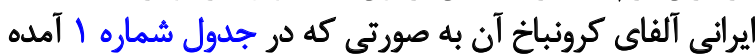

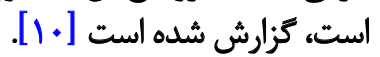

2. Mindfulness Attention Awareness Scale (MAAS)

3. Integrative Self Knowledge (ISK)

جدول آ. آلفاي كرونباخ يرسشنامه ضربهائ روانى دوران كودكى

\begin{tabular}{|c|c|}
\hline آلفاى كرونباخ & بُعد \\
\hline .199 & كودى آزارى جسمى \\
\hline$\cdot M r$ & كودى آزارى جنسى \\
\hline$\cdot N$ & غفقلت يا بيىتوجهي \\
\hline - /Ar & سوء تعذيله \\
\hline$\cdot M$ & كودك آلزارى عاطفى \\
\hline.$/ A$ & كل \\
\hline
\end{tabular}




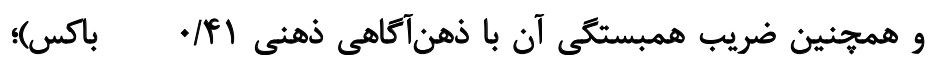

r. مفروضه يكساني واريانس ها (آزمون لوين يا لونز)؛ f. أهمبستَى متقابل بين متغيرهاى وابسته.

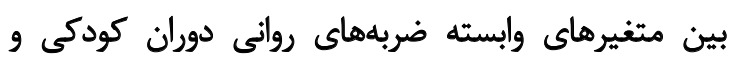

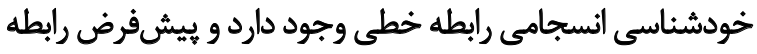

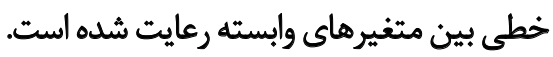

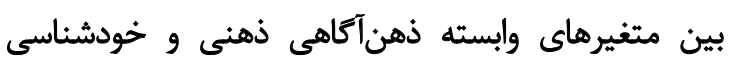

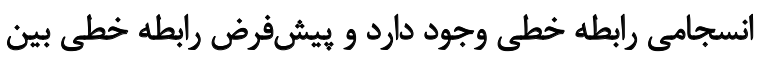
متغيرهاى وابسته رعايت شده است.

با بررسى نمودارى كه از رابطه بين متغيرهاي وابسته به دست

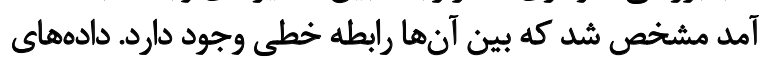

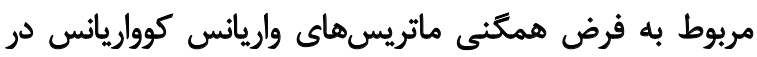
جدول شماره 8 ارائه شده است ماتريت

برابرى واريانسهاى متغيرهاى وابسته ضربهائهاى دوران

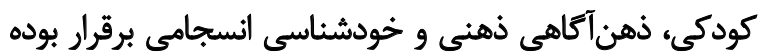
و اجراى آزمون مانووا امكانيذير ذاست خون.

با توجه به نتايج آزمون لونز و معنادار نبودن آن برائ براي متغيرهاي

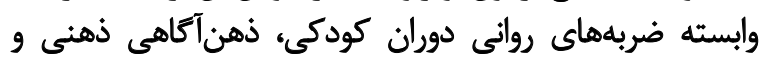

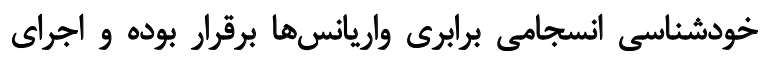
آزمون مانووا امكانيذي انسير است برابرى

نتايج آزمون لامبداي ويلكز در مورد متغير تركيبى، معنى دار ماري

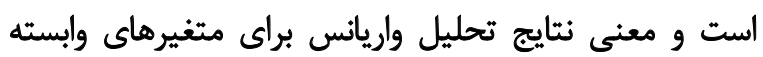

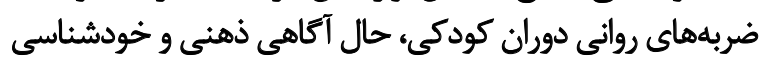
انسجامى در جدول شماره لا ارائه شده است

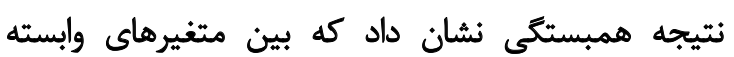

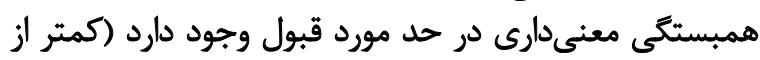

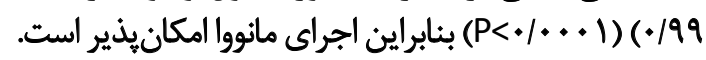

بررسى ميانكين و انحراف استاندارد ضربههاي روانى دوران

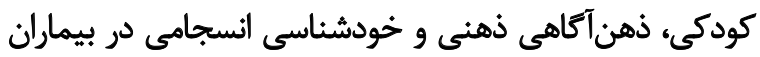
مبتلا به سرطان و جمعيت عادى درئ در جدول شماره 1 ارائه شده

از ملاحظه ارقام جدول شماره 1 مشخص مى مشود كه بين

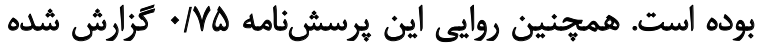

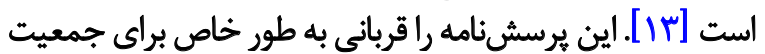

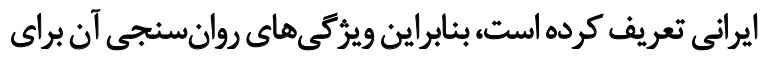
جمعيت غيرايرانى در دسترس نيست. شيوها إبرا

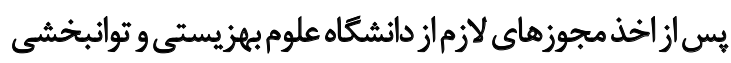

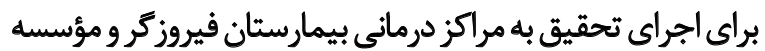

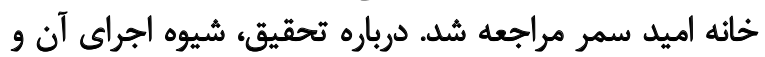

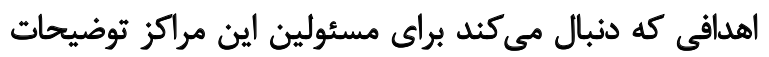

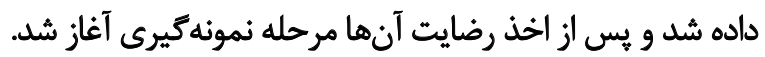

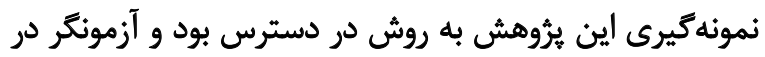

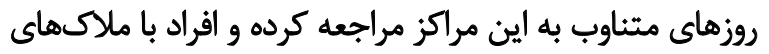

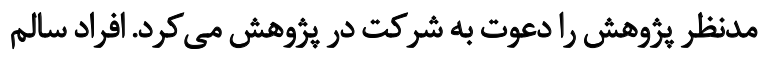

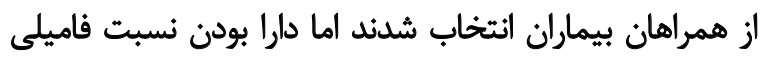

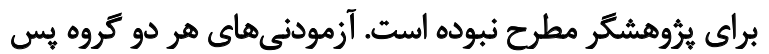

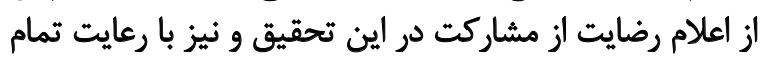

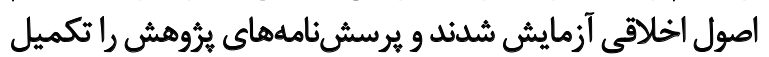

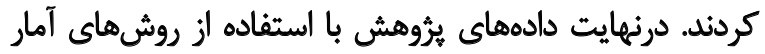

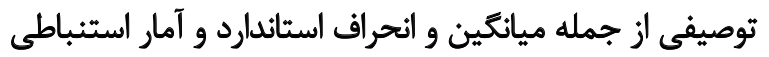

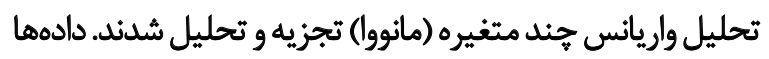

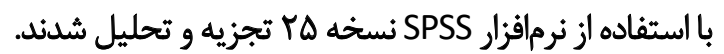

يالثتهها

جدول شماره Y ميانكين سن آزمودنىها را نشان مي دهدد.

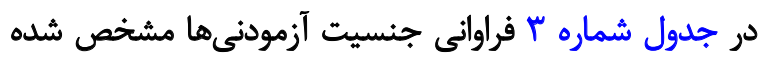

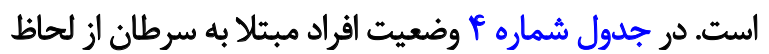

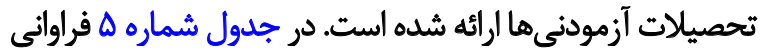
سطح تحصيلات افراد عادى مشاهده مى شودد.

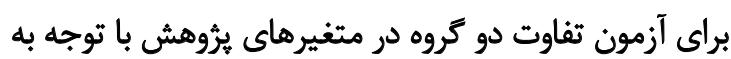

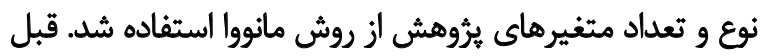

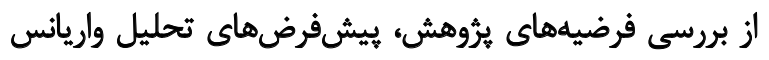

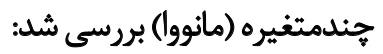
1. فرض رابطه خطى بين متغيرهاى وابسته؛ ז. فرض همبستگى ماتريسهاى واريانس كوواريانس (آزمون

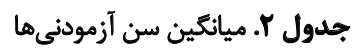

$$
\text { ميانئين }
$$

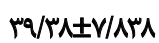

P)/AqEV/rqe

\section{أزمودنى ها}

اقراد مبئلا به سرطان

جمعيث عادى 
جدول r. قراوائى جنسيت آزمودئىها

\begin{tabular}{|c|c|c|c|}
\hline \multicolumn{2}{|c|}{ جمعيت عادى } & \multicolumn{2}{|c|}{ افراد مبتلا به سرطان } \\
\hline هرد & ij & مرد & نj \\
\hline 98 & $n^{\mu}$ & q. & na \\
\hline r/T درصد & A / مه درصد & T/K & A \\
\hline
\end{tabular}

\begin{tabular}{|c|c|}
\hline فراواتى (درصد) & تحصيلات \\
\hline $1 \varphi(1 V / \Delta)$ & دييلم و بايينتر \\
\hline $\mathrm{rg}(\mathrm{TA} / \mathrm{Q})$ & فوق دييلم \\
\hline EA (FNQ) & ليسائس \\
\hline $\operatorname{IV}(\mathrm{M} / \mathrm{Y})$ & فوت ليسائس \\
\hline$r(1 / P)$ & دكترى \\
\hline Irq (1..) & كل \\
\hline
\end{tabular}

جدول ه. فراواني تحصيلات جمعيت عادى

\begin{tabular}{|c|c|}
\hline فراواني (درصد) & تجصيات \\
\hline $9(8 / \Delta)$ & دييلم و بايينتر \\
\hline$M(T r / \pi)$ & فوق دييلم \\
\hline$W(\Delta \Delta / F)$ & ليسائس \\
\hline$r \cdot(I f / F)$ & فوق ليسانس \\
\hline$r\left(1 / r^{*}\right)$ & دكترى \\
\hline $149(1.0)$ & كل \\
\hline
\end{tabular}

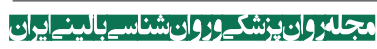

جدول و. همكنسازى كروههاى مطالعه بر حسب اطلاعات جمعيتشناختى جنس، سن و تحصيلات

\begin{tabular}{|c|c|c|c|c|}
\hline خطاى انحراف معيار & ميانتين & تعداد & كروه & متغيرها \\
\hline$+M I f+4$ & $r+1+r q+ \pm$ r/ArTAP & 149 & افراد عادى & \multirow[b]{2}{*}{ سن } \\
\hline . MANTI & rNAqQYT Y/IFITP & 149 & اقراد مبثّلا به سرطان & \\
\hline $.1 \cdot n$ & $1 / \Delta r \pm \cdot / \Delta+1$ & 149 & افراد عادى & \multirow{2}{*}{ جنس } \\
\hline .. $\mathrm{PH}$ & $1 / \Delta / \pm+/ F q$ & 179 & اقراد مبتلا به سرطان & \\
\hline .1 .9$. & $r / M \pm 1 / .98$ & ira & افراد عادى & \multirow{2}{*}{ آموزش } \\
\hline .1 .98 & $r / M \pm 1 / 1.1$ & IHA & افراد مبئلا به سرطان & \\
\hline
\end{tabular}


جدول Y. تحليل واريانس براى متغيرهاى وابسته ضربههاى رواتى دوران كودكى، حال آكاهى ذهنى و خودشناسى انسجامى

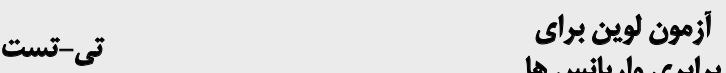

برابرى واريانس هراي

\begin{tabular}{|c|c|c|c|c|c|c|c|c|c|}
\hline \multicolumn{2}{|c|}{ 90\% سطح اطمينان } & \multirow{2}{*}{$\begin{array}{l}\frac{1}{3} \\
\frac{3}{3} \\
\frac{3}{3}\end{array}$} & \multirow{2}{*}{ 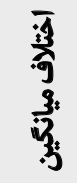 } & \multirow{2}{*}{ 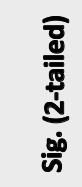 } & \multirow{2}{*}{ df } & \multirow{2}{*}{$t$} & \multirow{2}{*}{ Sig. } & $\mathbf{F}$ & \multirow[t]{2}{*}{ متغيرها } \\
\hline حداكثر & حداقل & & & & & & & & \\
\hline
\end{tabular}

واريانس برابر

واريانس نابرابر

واريانس برابر

واريانس نابرابر

واريانس برابر

واريانس نابرابر

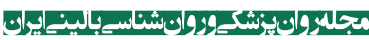

جلدول 1. توزيع مؤلفهاى متغيرهاى وابسته ضربههاى روانى دوران كودكى، ذهن آكاهى ذهنى وخودشناسى انسجامى در بيماران مبتلا به سرطان باجمعيت عادى $(n=r Y \wedge)$

\begin{tabular}{|c|c|c|}
\hline جمعيت عادى & بيماران مبثلا به سرطان & مؤلقهها \\
\hline FV/IYEIY/AIF & AV/TVEIT/\&AA & ضربههاي رواثي دوران كودكى \\
\hline ENFVIID/EAY & $\Delta r / T+ \pm I \& / M M$ & ذهن أكاهى ذهنى \\
\hline$r N \cdot q \pm q / 5 \cdot V$ & PNIII1.1.8. & خودشناسي انسجامي \\
\hline
\end{tabular}

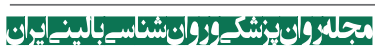

جدول 9 و واريانس هئدمتغيره نسبت F براى اندازه متغيرهاى تركيبى ضربههاى روانى دوران كودكى، ذهن آكاهى ذهنى و خودشناسى انسجامى

\begin{tabular}{|c|c|c|c|c|}
\hline اتا & مقدار احتمال & $F_{(T V E / M)}$ & ارزش & منيع \\
\hline . $/ \mathrm{A \Delta V}$ & $<+/ *+$ & $\Delta F q / T A V$ & . & متغير تركيبى (كروه) \\
\hline
\end{tabular}

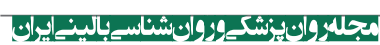




\begin{tabular}{|c|c|c|c|c|c|c|}
\hline اندازه اثي & مقدار احتمال & در جه آزادى خطا & درجه أزادي & $\mathbf{F}$ & مقدار & نام آزمون \\
\hline - /NAV & $<\cdot 1 . .1$ & $m e$ & $r$ & $\Delta F q / T A V$ & . /AOY & ائر ييلايع \\
\hline - IAAV & $<+1 .+1$ & $r r^{f}$ & $r$ & DFq/rAV & $. / N F+$ & لامبداى ويلكز \\
\hline - /NAV & $<+1 \cdot+1$ & $r r^{\circ}$ & r & DPq/TAV & $91 \cdot 10$ & اثر هاتلينى \\
\hline - /Aar & $>.1 . .1$ & $r{ }^{f}$ & $r$ & DFq/TAV & 81.10 & بزركترين ريشه روى \\
\hline
\end{tabular}

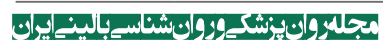

جدول Iا. تحليل حاصل از تحليل واريانس تكمتغيرى براي متغير ضربهماي روانى دوران كودكى

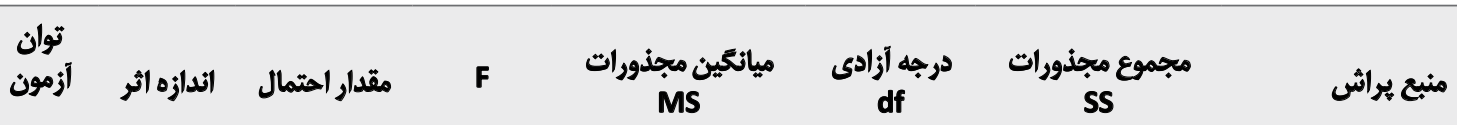

\begin{tabular}{|c|c|c|c|c|c|c|c|}
\hline 1 & .1894 & $<+1 .+1$ & STV/DAF & $\|T+F\| / \Delta N E$ & 1 & $\| H+F I / O N E$ & ضربه ها روانى دوران كودكى \\
\hline & & & & $I V \Delta / M V$ & MVE & $r A \Delta+r / r+q$ & خطا \\
\hline
\end{tabular}

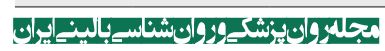

جدول با. تحليل حاصل از تحليل واريانس تكمتغيرى براي متغير خودشئاسى انسجامى

\begin{tabular}{|c|c|c|c|c|c|c|c|}
\hline آزمون & اندازه اثر & مقدار التتمال & $\mathbf{F}$ & $\begin{array}{c}\text { ميانكين مجذوروات } \\
\text { MS }\end{array}$ & درجه أزادى & $\begin{array}{c}\text { مجموع مجذورات } \\
\text { SS }\end{array}$ & منبع يراث \\
\hline
\end{tabular}

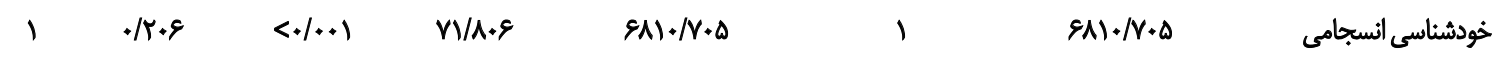

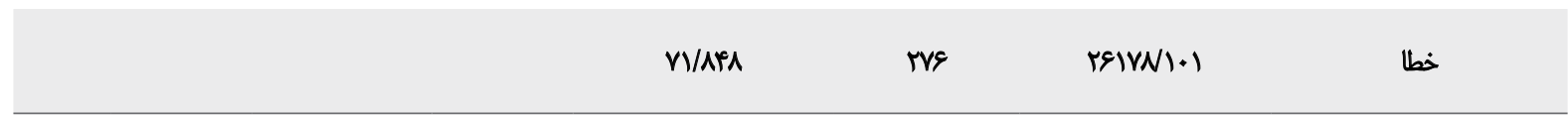

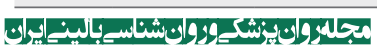

جدول با. تحليل حاصل از تحليل واريانس تكمتغيرى براى متغير ذهن آكاهى ذهنى

\begin{tabular}{|c|c|c|c|c|c|c|c|}
\hline آزمون & اندازه اثر & مقدار احتمال & $\mathbf{F}$ & ميانكين مجنورات & 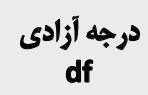 & مجموع مجذورات & منبع براش \\
\hline \multirow[t]{2}{*}{1} &.$/ 199$ & $<\cdot 1 \cdot .+1$ & ENTAE & $|A| \& \mid / q . \mu$ & 1 & $|A| \& \mid / 9.4$ & ذهن أكاهي ذهني \\
\hline & & & & red/AVq & rve & nัтง9/91f & خطا \\
\hline
\end{tabular}


بحث

هدف اصلى يُروهش حاضر مقايسه ضربهائ روانى دوران

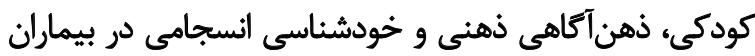

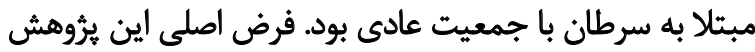

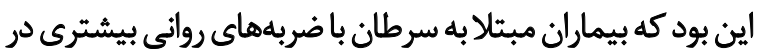

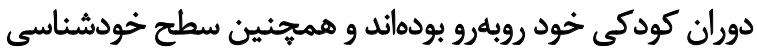

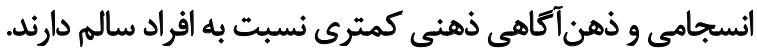

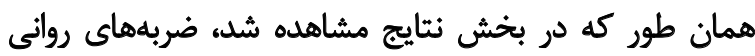

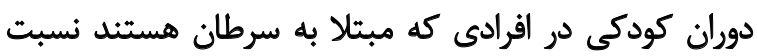

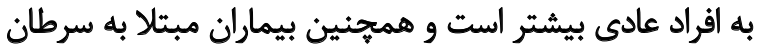

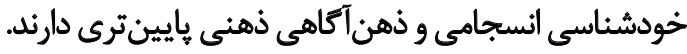

نتيجه بررسى سؤال اول مبنى بر اينكه آيا اختلاف معناديار

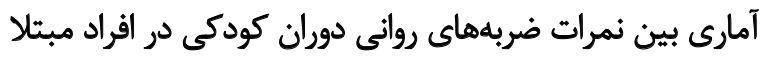

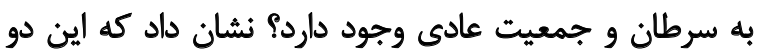

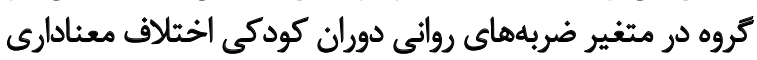

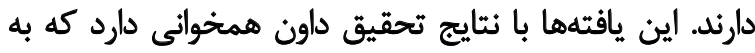

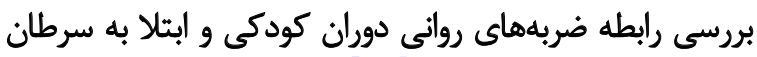

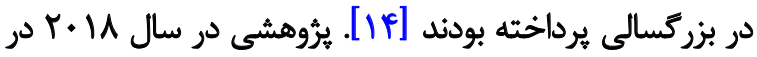

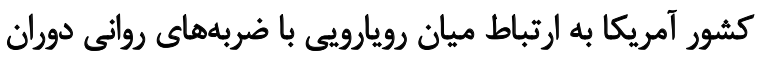

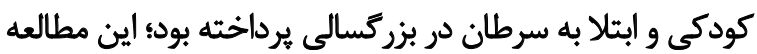

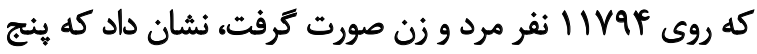

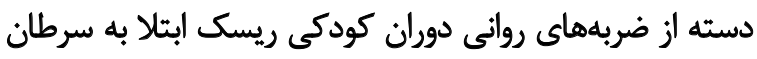

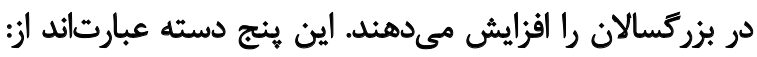

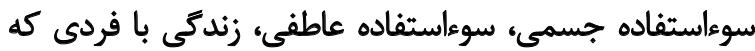

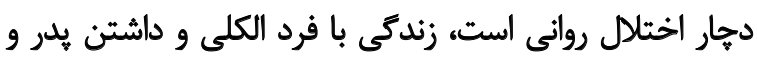
مادرى كه جدا زندگى مى كنيند يا طلاق كرفتهاند [1ه]

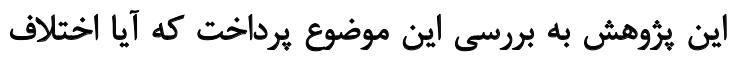

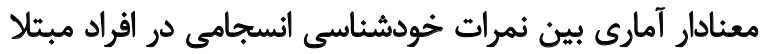

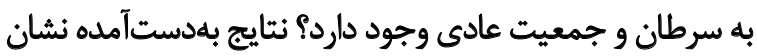

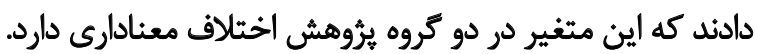

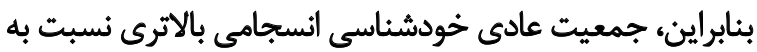

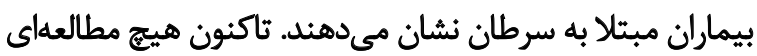

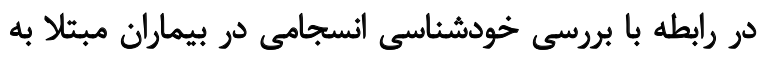

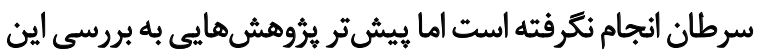

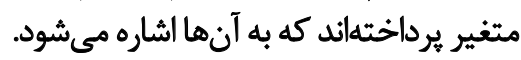

صالح ميرحسينى به بررسى رابطه خودشناسى انسجامى با بانيا

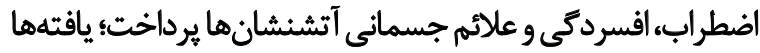

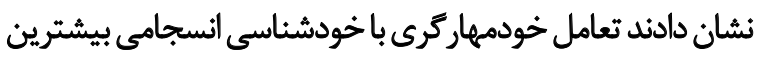

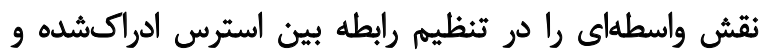

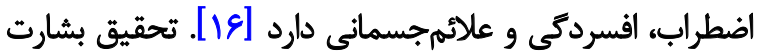

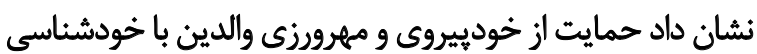

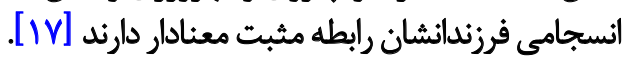

ميانكين بيماران مبتلا به سرطان و جمعيت عادى در متغيرهاي

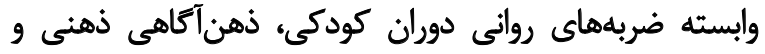

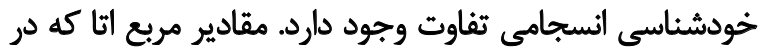

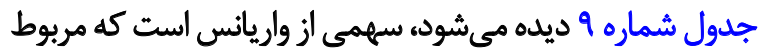

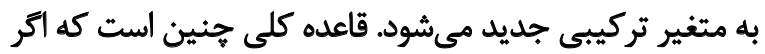

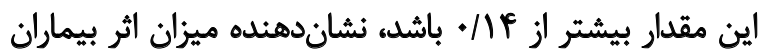

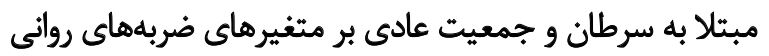

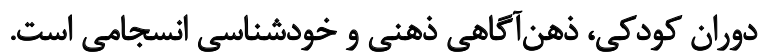

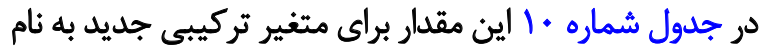

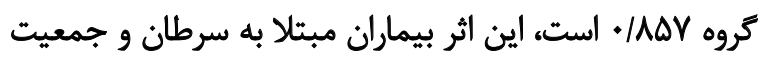

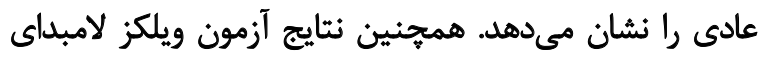

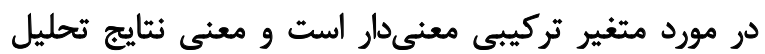

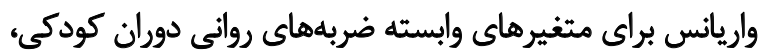

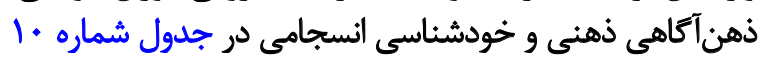

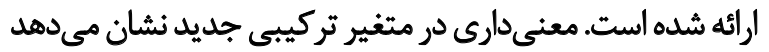

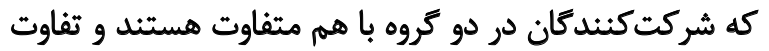

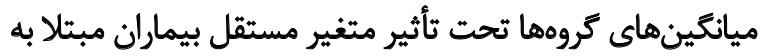

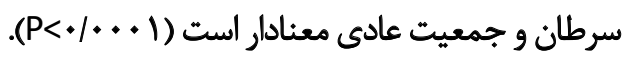

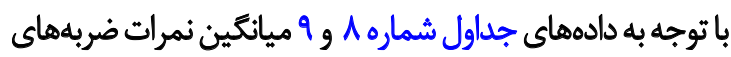

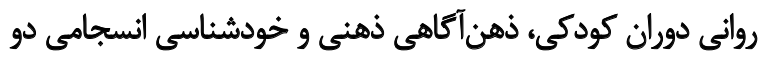

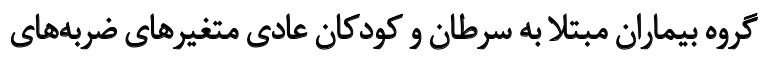

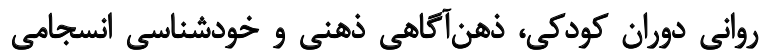

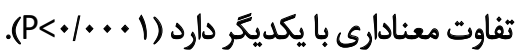

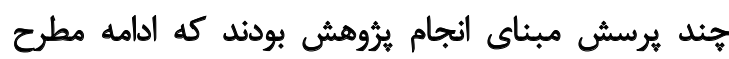

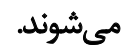

آيا اختلاف معنادار آمارى بين نمرات ضربهادهاى رواند

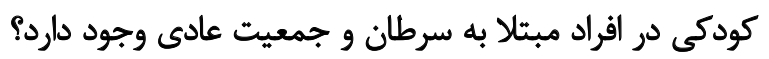
با توجه به دادههاى جدول دول شماره

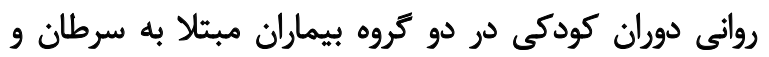

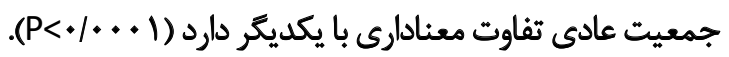
آيا اختنلاف معنادار آمارى بين نمرات خودشناسي انسجامى

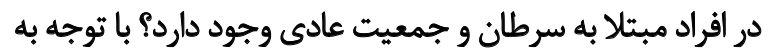

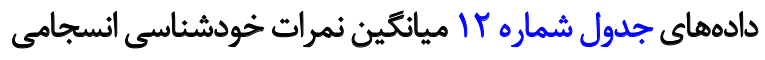

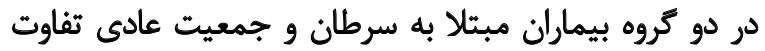

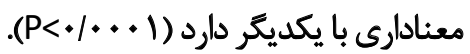

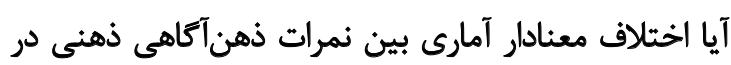

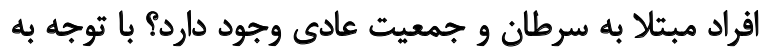

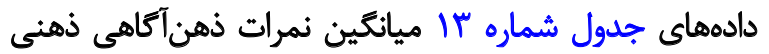

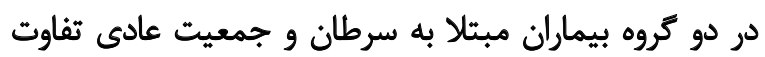

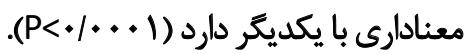




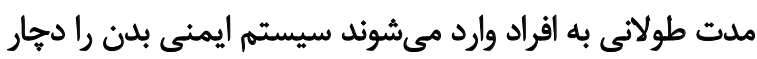

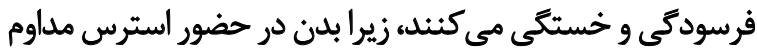

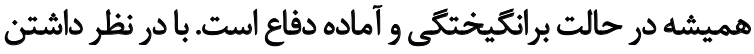

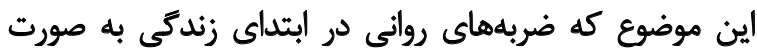

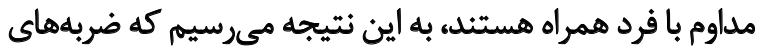

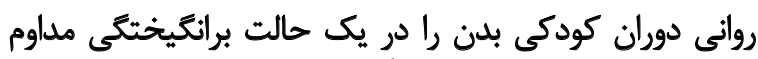

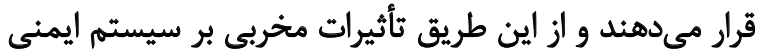

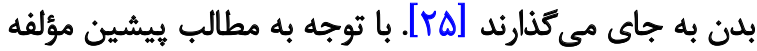

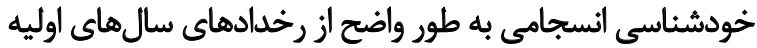

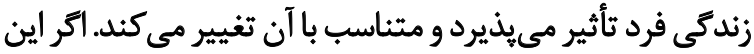

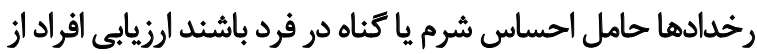

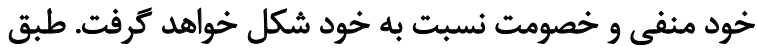

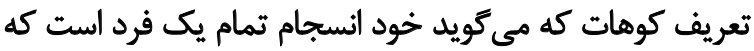

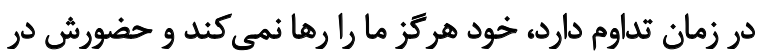

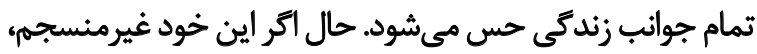

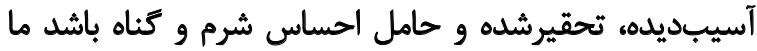

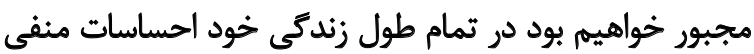

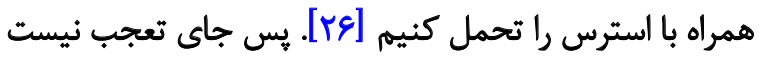

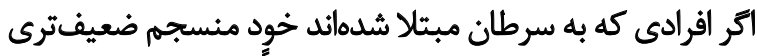

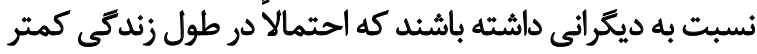

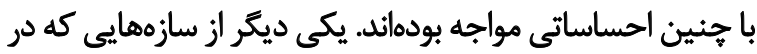

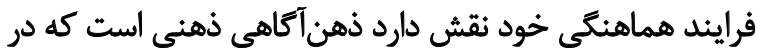

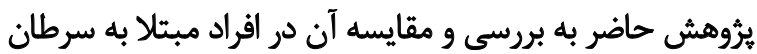

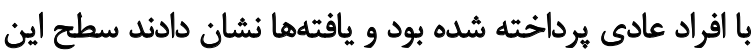

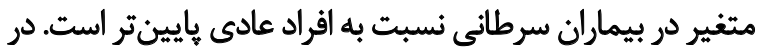

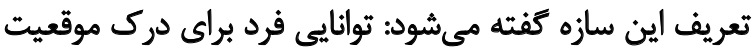

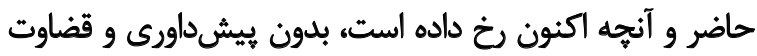

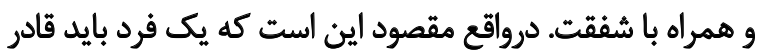

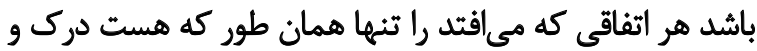

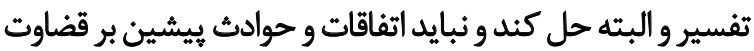

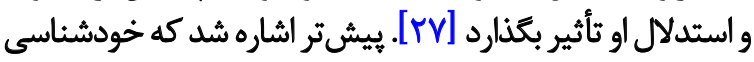

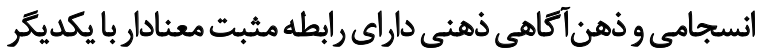

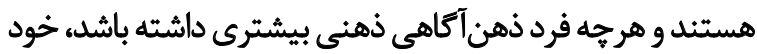

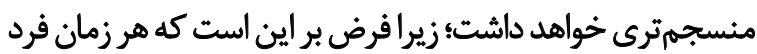

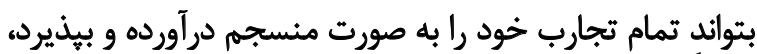

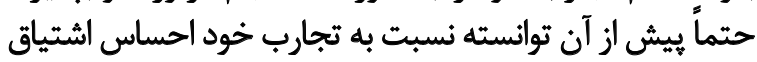

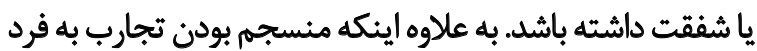

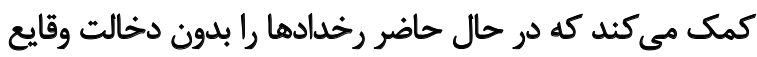

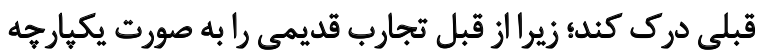

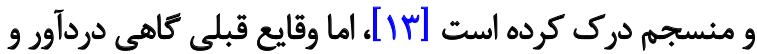

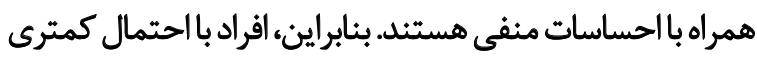

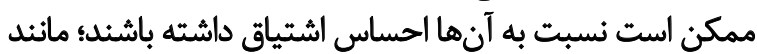

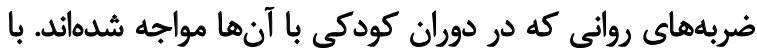

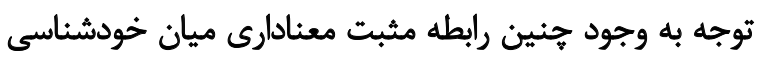

اين بُروهش هميجنين به بررسى اين نكته برداخت كه آيا

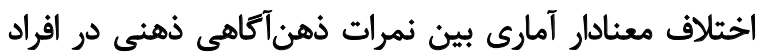

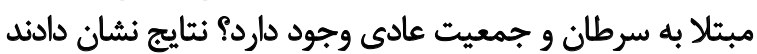

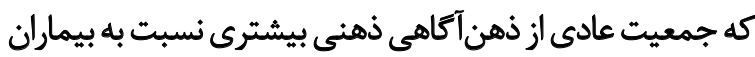

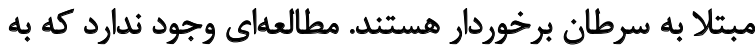

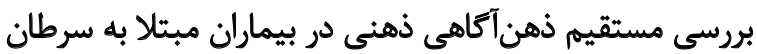

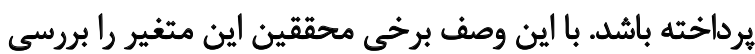

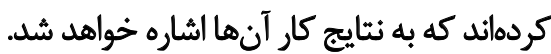

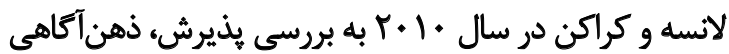

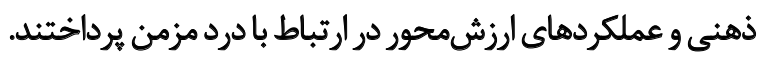

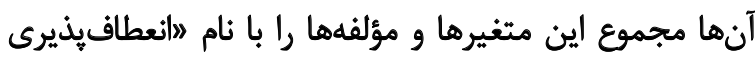

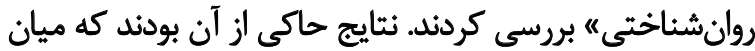

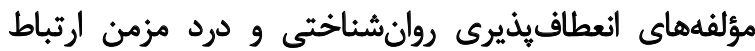

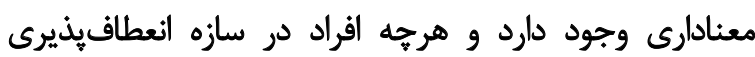

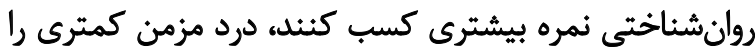

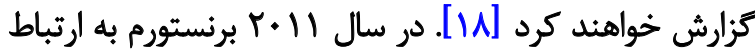

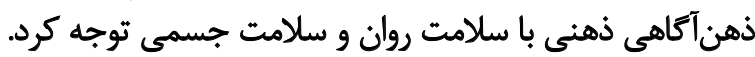

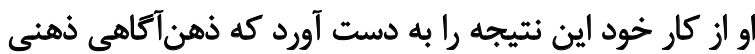

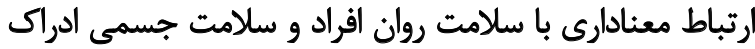

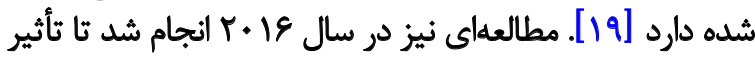

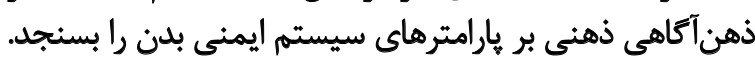

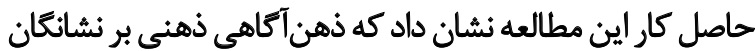

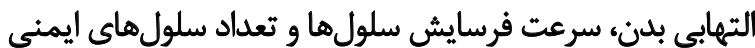

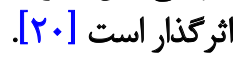

ابتلا به سرطان و ناتزير بودن از زندگى با اين بيمارى مى تواند

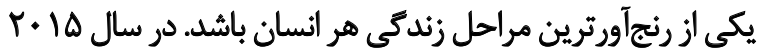

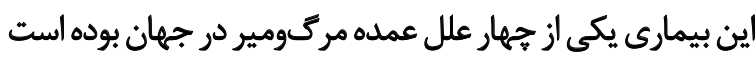

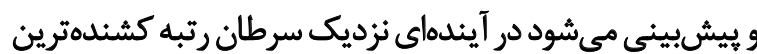

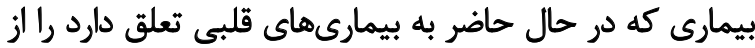

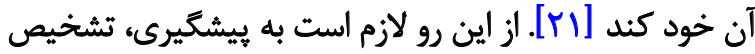

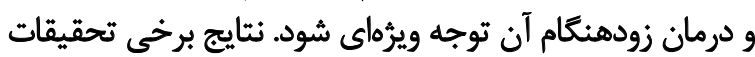

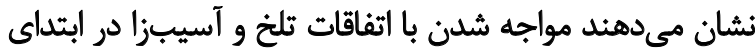

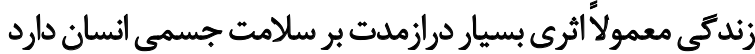

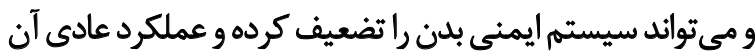

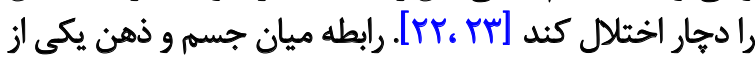

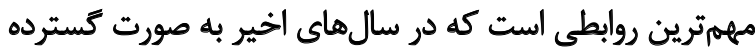

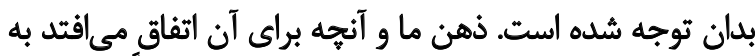

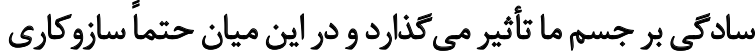

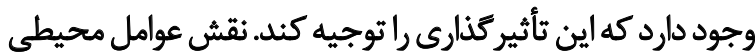

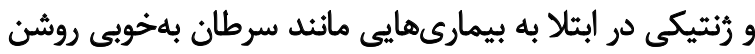

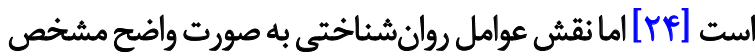
نيست و هنوز براى بسيارى از محققين محل سؤ بوال است. همان بان

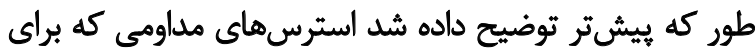




\section{ملاحظات اخلاقى

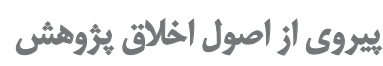

اين بثروهش با رعايت موازين اخلاقى و اصول اخلاق در ثروهش

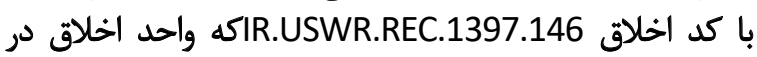

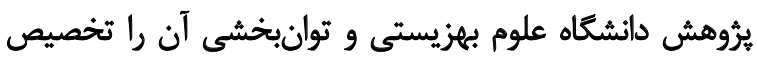

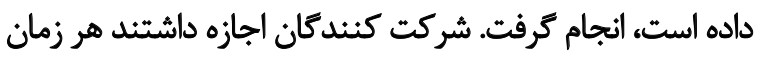

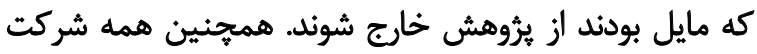

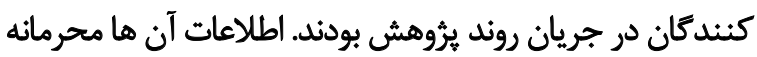

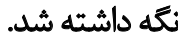

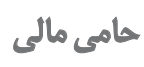

اين يُروهش بركرفته از يايان نامه كارشناسى ارشد نويسنده دوم

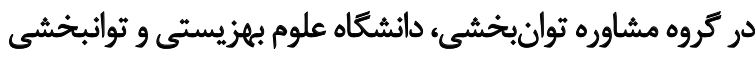

\section{مشار كت نويسندكّان}

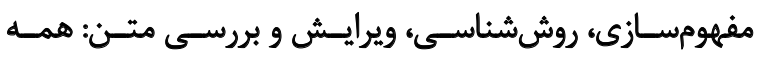

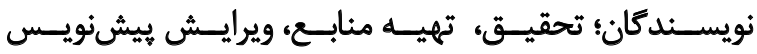

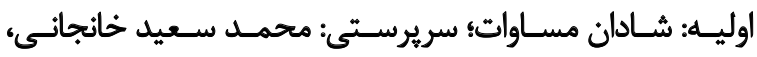

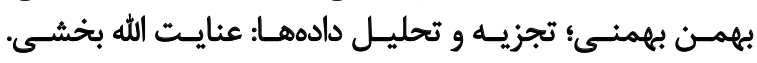

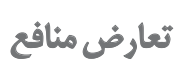

بنابر اظهار نويسندكان اين مقاله هيج تضاد مثافعى ندارد.

$$
\text { تشيكر و قثدرواني }
$$

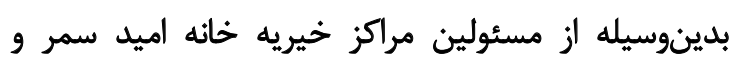

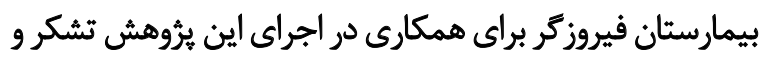
قدرداني مي كنيمه.

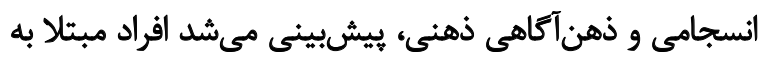

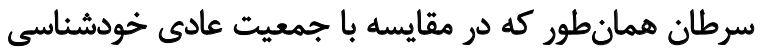

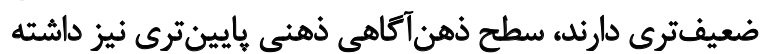
باشند و نتايج اين موضوع رانئ سأييد كردند.

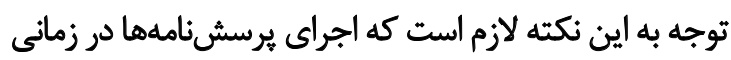

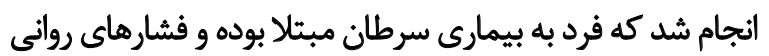

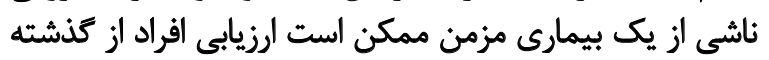

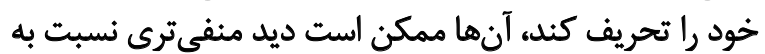

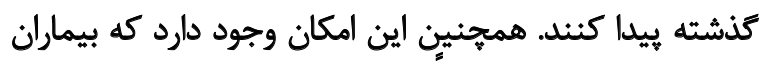

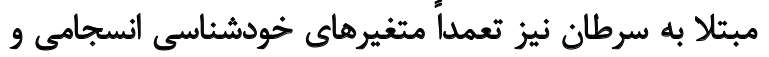

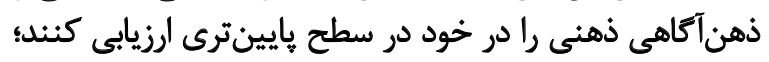

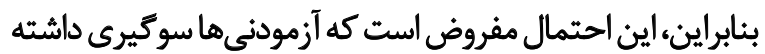
و بر نتايج تأثير كذاشته باشند.

$$
\text { نتيجليرى }
$$

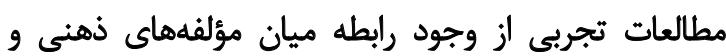

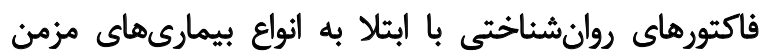

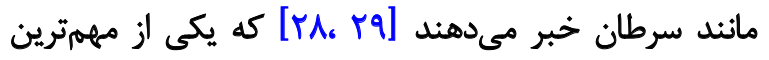

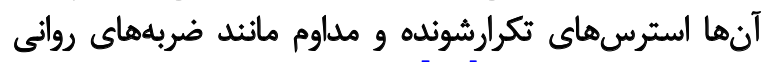

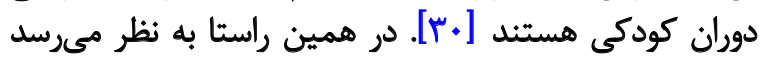

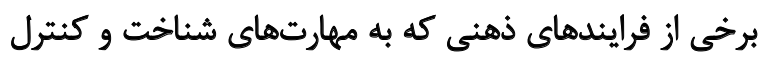

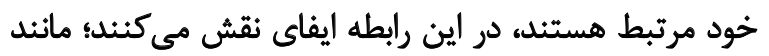

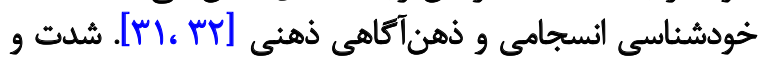

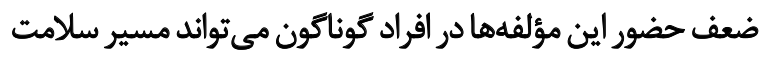

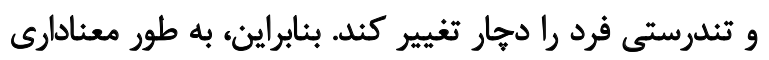

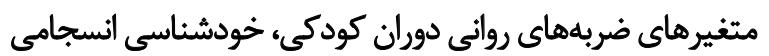

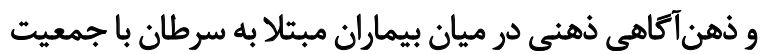
عادى متفاوت هيتئد. با توجه به اينكه يُروهش حاضر بر بيماران مبتلا به سرطان

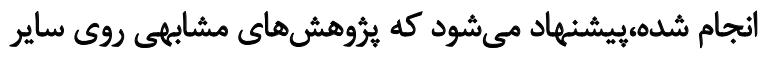

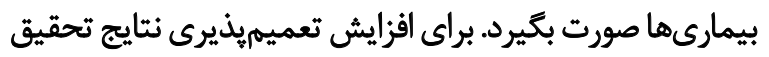

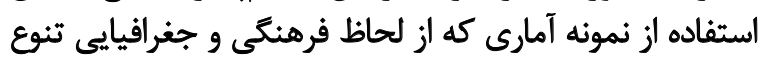

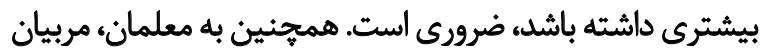

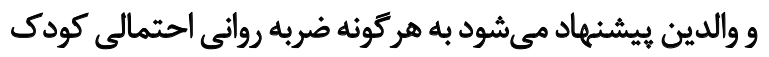
توجه ويزٔه كنند تا امكان بيشكيرى به موقع فراهم شونه روني

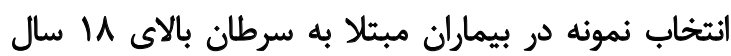

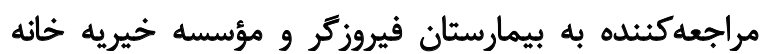

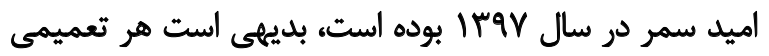

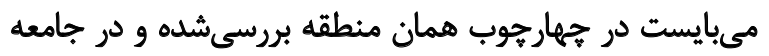

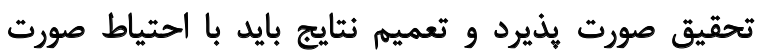

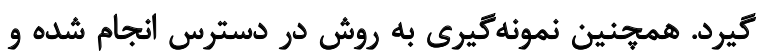
تعميمهيذيرى نياز به احتياط دارد. 


\section{References}

[1] Dincher TR, Harkness GA. Medical-Surgical Nursing. Philadelphia: Harkness and Dincher Publishers; 2000.

[2] Reiche EM, Nunes SO, Morimoto HK. Stress, depression, the immune system, and cancer. The Lancet Oncology. 2004; 5(10):61725. https://www.sciencedirect.com/science/article/abs/pii/ S1470204504015979

[3] Ferraro KF, Shippee TP. Aging and cumulative inequality: How does inequality get under the skin? The Gerontologist. 2009; 49(3):333-43. [DOI:10.1093/geront/gnp034] [PMID] [PMCID]

[4] Woods LM, Rachet B, Coleman MP. Origins of socio-economic inequalities in cancer survival: A review. Annals of oncology. 2006; 17(1):5-19. [DOI:10.1093/annonc/mdj007] [PMID]

[5] Omidbeiki M, Khalili SH, Gholamali Lavasani M, Ghorbani $\mathrm{N}$. The relationship between mindfulness and integrative self-knowledge with marital satisfaction. Journal of Psychology. 2014; 18(3):327-41. https://www.magiran.com/ paper/1319970?lang=en

[6] Ghorbani N, Cunningham CJ, Watson PJ. Comparative analysis of integrative self-knowledge, mindfulness, and private self-consciousness in predicting responses to stress in Iran. International Journal of Psychology. 2010; 45(2):147-54. [DOI:10.1080/00207590903473768] [PMID]

[7] Soltani Azemat E, Mohammadian A, Azizi S, Golzar Pour M, Yarmohammadi Vasel M. [A comparative examination of childhood traumas in sex addicts and normal individuals (Persian)]. The Neuroscience Journal of Shefaye Khatam. 2017; 5(2):43-51. http://shefayekhatam.ir/article-1-1379-en.html

[8] Brodsky BS, Mann JJ, Stanley B, Tin A, Oquendo M, Birmaher B. Familial transmission of suicidal behaviour: Factors mediating the relationship between childhood abuse and offspring suicide attempts. The Journal of Clinical Psychiatry. 2008; 69(4):584. [DOI:10.4088/JCP.v69n0410] [PMID] [PMCID]

[9] Roy A. Combination of family history of suicidal behavior and childhood trauma may represent correlate of increased suicide risk. Journal of Affective Disorders. 2011; 130(1-2):205-8. [DOI:10.1016/j.jad.2010.09.022] [PMID]

[10] Angelakis I, Gillespie EL, Panagioti M. Childhood maltreatment and adult suicidality: A comprehensive systematic review with meta-analysis. Psychological Medicine. 2019; 49(7):1057-78. [DOI:10.1017/S0033291718003823]

[11] Ghorbani N, Watson PJ, Weathington BL. Mindfulness in Iran and the United States: Cross-cultural structural complexity and parallel relationships with psychological adjustment. Current Psychology. 2009; 28(4):211. [DOI:10.1007/s12144-009-9060-3]

[12] Ghorbani N, Watson PJ, Bing MN, Davison HK, LeBreton D. Two facets of self-knowledge: Cross-cultural development of measures in Iran and the United States. Genetic, Social, and General Psychology Monographs. 2003; 129(3):238-68. https:/ / www. proquest.com/openview/e7e586e83b4358a08e7865f387cab18d/ 1 ?pq-origsite $=$ gscholar $\& \mathrm{cbl}=36144$

[13] Ghorbani N, Watson PJ, Hargis MB. Integrative Self-Knowledge Scale: Correlations and incremental validity of a crosscultural measure developed in Iran and the United States. The Journal of Psychology. 2008; 142(4):395-412. [DOI:10.3200/ JRPL.142.4.395-412] [PMID]
[14] Holman DM, Ports KA, Buchanan ND, Hawkins NA, Merrick MT, Metzler M, et al. The association between adverse childhood experiences and risk of cancer in adulthood: a systematic review of the literature. Pediatrics. 2016; 138(Supplement 1):S81-91. [DOI:10.1542/peds.2015-4268L] [PMID] [PMCID]

[15] Alcalá HE, Mitchell EM, Keim-Malpass J. Heterogeneous impacts: adverse childhood experiences and cancer screening. Cancer Causes \& Control. 2018; 29(3):343-51. https://link.springer. com/article/10.1007/s10552-018-1007-2

[16] Salehmirhassani V, Ghorbani N, Alipour A, Farzad V. The mediating role of self knowledge process (integrative self knowledge and mindfulness) and self control in regulating the relationship between perceived and objective stress and anxiety, depression and physical symptoms. Journal of Research in Psychological Health. 2016; 10(3):1-15. http://rph.khu.ac.ir/article-1-2726-en. html

[17] Besharat MA, Bazzazian S, Ghorbani N, Asghari M. [Predicting Children's integrative self-knowledge in terms of parenting characteristics of parent (Persian)]. Journal of Family Researc. 2014; 10(1):65-78. https://nimaghorbani.com/wp-content/uploads/2018/08/

[18] Lance M. McCracken, Sophie C. Velleman. Psychological flexibility in adults with chronic pain: A study of acceptance, mindfulness, and values-based action in primary care. Pain. 2010; 148(1): 141-7. [DOI:10.1016/j.pain.2009.10.034] [PMID

[19] Bränström R, Duncan LG, Moskowitz JT. The association between dispositional mindfulness, psychological well-being, and perceived health in a Swedish population-based sample. British Journal of Health Psychology. 2011; 16(2):300-16. [DOI:10.1348/135910710X501683] [PMID] [PMCID]

[20] Black DS, Slavich GM. Mindfulness meditation and the im mune system: A systematic review of randomized controlled trials. Annals of the New York Academy of Sciences. 2016; 1373(1):13. [PMCID] [PMID]

[21] Siegel RL, Miller KD, Jemal A. Cancer statistics, 2015. CA: a Cancer Journal for Clinicians. 2015; 65(1):5-29. [DOI:10.3322/ caac.21254] [PMID]

[22] Danese A, Pariante CM, Caspi A, Taylor A, Poulton R. Childhood maltreatment predicts adult inflammation in a life-course study. Proceedings of the National Academy of Sciences. 2007; 104(4):1319-24. [DOI:10.1073/pnas.0610362104] [PMID] [PMCID]

[23] Cicchetti D, Rogosch FA. The impact of child maltreatment and psychopathology on neuroendocrine functioning. Development and Psychopathology. 2001; 13(4):783-804. [DOI:10.1017/ S0954579401004035] [PMID]

[24] Colditz GA, Sellers TA, Trapido E. Epidemiology -identifying the causes and preventability of cancer? Nature Reviews Cancer. 2006; 6(1):75-83. [DOI:10.1038/nrc1784] [PMID]

[25] Danese A, Baldwin JR. Hidden wounds? Inflammatory links between childhood trauma and psychopathology. Annual Review of Psychology. 2017; 68:517-44. [DOI:10.1146/annurevpsych-010416-044208] [PMID]

[26] Gilbert P, Miles JN. Sensitivity to Social Put-Down: it's relationship to perceptions of social rank, shame, social anxiety, depression, anger and self-other blame. Personality and Individual Differences. 2000; 29(4):757-74.[DOI:10.1016/S0191-8869(99)00230-5] 
[27] Kabat-Zinn J, Hanh TN. Full catastrophe living: Using the wisdom of your body and mind to face stress, pain, and illness. London: Delta; 2009.

[28] Black JM, Hawks JH, Keene AM. Clinical management for positive outcomes. Medical surgical nursing. Philadelphia: Elsevier Saunders; 2005. https://books.google.com/ books?id=XDNtAAAAMAAJ\&q=

[29] Tazebay UH, Wapnir IL, Levy O, Dohan O, Zuckier LS, Zhao $\mathrm{QH}$, et al. The mammary gland iodide transporter is expressed during lactation and in breast cancer. Nature Medicine. 2000; 6(8):871-8. https://www.nature.com/articles/nm0800_871

[30] Kemp BR, Ferraro KF, Morton PM, Mustillo SA. Early origins of adult cancer risk among men and women: Influence of childhood misfortune? Journal of Aging and Health. 2018; 30(1):140-63. [DOI:10.1177/0898264316670049]

[31] Kreitler S, Chaitchik S, Kreitlers H. Repressiveness: Cause or result of cancer? Psycho-oncology. 1993; 2(1):43-54. [DOI:10.1002/ pon.2960020107]

[32] Varela FJ, Anspach M. Immunknowledge: the process of somatic individuation. In: Thompson WI, editor. Gaia 2: Emergence The New Science of Becoming. New York: Lindisfarne. 1991. https:/ / books.google.com/books?hl=en\&lr=\&id=1jSwEHBMEi EC\&oi=fnd\&pg=PA11\&dq 